\title{
STRAF - UND STRAFPROZESSRECHT IM KOSOVO
}

Prof. dr. iur. Islam Qerimi, LL.M.*

Prof. Ass. dr. Bedri Bahtiri**

\author{
UDK 343.1(497.115) \\ https://doi.org/10.30925/zpfsr.39.3.12 \\ Ur.: 30. siječnja 2018. \\ Pr.: 15. rujna 2018. \\ Stručni rad
}

\section{Zussamenfassung}

Nach einer wechselvollen Geschichte konnte der Kosovo nach Erlangung der Unabhängigkeit erstmals ein eigenes Straf- und Strafprozessrecht erlassen. Der folgende Beitrag beschreibt das geltende kosovarische Recht und untersucht es u.a. darauf hin, ob es den Vorgaben der Verfassung und der einschlägigen völkerrechtlichen Verträge entspricht. Beim Erlass des neuen Strafrechts scheint ein gravierendes Versäumnis des Gesetzgebers das ,, Vergessen “eines Delikts der fahrlässigen schweren Körperverletzung zu sein, obwohl ein solcher Tatbestand in dem vorangehenden StGB noch enthalten war. Das neue Strafprozessrecht wurde durch einige angelsächsische Elemente angereichert und entspricht im Wesentlichen den menschenrechtlichen Vorgaben der Verfassung und der EMRK. Für jugendliche Straftäter gilt ein besonderes Strafbemessungs- und Verfahrensrecht, das in einem eigenen Jugendgerichtsgesetzbuch niedergelegt ist. Die Regeln über die strafrechtliche Mediation können sich auf alte gewohnheitsrechtliche Traditionen der Streiterledigung stützen.

Schlüsselwörter: Strafrecht, Strafprozessrecht, Jugendstrafrecht, Strafrechtsreform, Kosovo.

\section{EINLEITUNG}

Das Ziel dieses Beitrags ist es, die geschichtliche Entwicklung des Strafrechts und des Strafprozessrechts sowie die aktuelle Gesetzeslage im Kosovo darzustellen. Er gibt einen Überblick über die verschiedenen historischen Zeitperioden des Strafrechts im Kosovo. Zur Durchführung der Analyse der Entwicklung des Strafrechts und Strafprozessrechts im Kosovo werden zu Beginn die relevanten Forschungsfragen gestellt, die es im Rahmen dieser Arbeit zu beantworten gilt. Die Ergebnisse bestätigten zum großen Teil, dass die kosovarische Gesellschaft, wie andere Gesellschaften auch, im Umgang mit Rechtsbrechern ihren eigenen Weg

* Dr. sc. Islam Qerimi, Assistant Professor, Faculty of Law, University of Vienna, i_qerimi@ hotmai.com.

** Dr. sc. Bedri Bahtiri, Assistant Professor, Faculty of Law, University of Pristina, Kosovo; bedri. bahtiri@uni-pr.edu. 
durch die Bestimmung der Straftaten, der Verantwortlichkeit, der Schuld und der jeweiligen strafrechtlichen Sanktionen gegangen ist. Eine historische Besonderheit liegt in der parallelen Vielfalt der Strafgesetze. Die Schlussfolgerungen daraus sollen jedoch erst nach der Auswertung gezogen werden. Methodisch handelt es sich bei der vorliegenden Studie überwiegend um eine Literaturarbeit, die auf dem Studium des vorhandenen Schrifttums über das Strafrecht und Strafprozessrecht im Kosovo beruht.

Zur Durchführung einer Entwicklungsanalyse des Straf- und Strafprozessrechts im Kosovo werden zu Beginn die relevanten Forschungsfragen gestellt, die es im Rahmen dieser Arbeit zu beantworten gilt.

- Welche spezifische Entwicklung des Straf- und Strafprozessrechts in der Rechtsordnung im Kosovo gibt es?

- In welcher Weise unterscheiden sich die gesetzlichen Regelungen von dem alten Kanun?

- Entspricht das anwendbare Strafrecht im Kosovo der Verfassung der Republik Kosovo vom 17.2.2008 (in der Folge: VerfKos) und den internationalen Standards über Menschenrechte und Grundfreiheiten?

- Hat der Kosovo die zahlreichen Nebenstrafgesetze den EU-Standards angepasst?

- Müssen am Strafrecht und Strafprozessrecht im Kosovo noch Änderungen durchgeführt werden?

\section{DIE ZEITPERIODEN DER GESCHICHTLICHEN ENTWICKLUNG}

\subsection{DAS STRAFRECHT IM KOSOVO VOM 15. BIS ZUM 20. JAHRHUNDERT}

Besondere Bedeutung für das kosovarische Recht kommt dem Umstand zu, dass in den albanischen Gebieten und damit auch im Kosovo über Jahrhunderte der sog. Kanun als eine Quelle des Gewohnheitsrechts galt. Der Kanun beinhaltete auch das strafrechtliche Gewohnheitsrecht. Zu den bedeutendsten Kanunen zählen der Kanun des Lek Dukagjini ${ }^{1}$, der Kanun des Skanderbeg ${ }^{2}$, der Kanun der Laberia ${ }^{3}$ und zahlreiche andere regionale Kanune. Es lässt sich feststellen, dass während der Anwendung des Kanuns nicht immer eine strenge Teilung des Strafrechts von

1 „Der Kanun des Lek Dukagjini, alb. Kanuni i Leke Dukagjinit, stellt die bekannteste Zusammentragung des albanischen Gewohnheitsrechts dar. Dieses ursprünglich ungeschriebene Rechtssystem bestimmte die wesentlichen Aspekte des Sozialverhaltens in den abgelegenen und sonst gesetzlosen Gegend Nordalbaniens.“: Elsie, Robert: Vorwort in: Der Kanun. Das albanische Gewohnheitsrecht nach dem sogenannten Kanun des Leke Dukagjini, kodifiziert von Shtjefen Gjeqovi, ins Deutsche übersetzt von Marie Amelie Freiin von Godin, Peja 2001, S. 5.

2 Illia, Frano, Kanuni i Skënderbeut, Milot 1993.

3 Elezi, Ismet, Kanuni i Labërisë, Tirana 2006. 
dem Zivilrecht durchgesetzt wurde. ${ }^{4}$ Während der osmanischen Herrschaft in der Zeit vom 15. bis zum 20. Jahrhundert wurden auch andere Strafgesetze wie die Scharia, osmanische Kanune und das türkische Strafgesetzbuch aus dem Jahre 1868 angewendet. ${ }^{5}$ Im Kosovo fand während dieser Zeit somit eine divergierende Vielfalt von Strafgesetzen parallel Anwendung.

\subsection{DAS STRAFRECHT IM KOSOVO IN DER ZEIT VON 1918 BIS 1941}

Nach dem Sieg gegen das osmanische Reich rief Albanien am 12.11.1912 seine Unabhängigkeit aus und wurde in den heutigen Grenzen anerkannt. Der Kosovo und andere albanische Gebiete, die außerhalb des neuen Staates geblieben waren, wurden unfreiwillig zunächst Serbien und nach dem Ersten Weltkrieg der Monarchie der Serben, Kroaten und Slowenen angeschlossen. Aufgrund dieser Tatsache wurde im Kosovo im Unterschied zu Albanien ein eigener Weg bei der Gestaltung des Rechtssystems beschritten. ${ }^{6}$ Während dieser Zeit hieß der Kosovo Südserbien. Es ist wichtig zu erwähnen, dass in diesem Staat im Jahre 1921 ein besonderes Gesetz über den Schutz der Sicherheit der Staatsordnung angenommen wurde ${ }^{7}$, welches aufgrund der angewandten Brutalität und der drakonischen Strafen als „Gesetz mit schlechtem Ruf für den Schutz des Staates" bezeichnet wurde. Des Weiteren wurde 1930 im Königreich Jugoslawien ein neues Strafgesetzbuch in Kraft gesetzt. ${ }^{8}$ Im ganzen Territorium des sog. SKS-Staates fanden die Kapitel IX und XI des serbischen Strafgesetzbuches Anwendung, die sich auf Ordnungswidrigkeiten und Straftaten gegen den Staat, den König und die Verfassung bezogen. Mit diesem Strafgesetzbuch wurde die albanische Bevölkerung nicht in Schutz genommen, sondern in vielen Fällen für vogelfrei erklärt. ${ }^{9}$

\subsection{DAS KOSOVARISCHE STRAFRECHT NACH DEM ZWEITEN WELTKRIEG}

Der Kosovo blieb auch nach dem Zweiten Weltkrieg unter serbischer und jugoslawischer Souveränität, weshalb auch weiterhin das jugoslawische Strafrecht

4 Pupovci, Syrja, Marrëdhëniet juridike civile në Kanunin e Lekë Dukagjinit, Prishtina, 1971, S. 63 und 67.

5 Omari, Luan, Luarasi Aleks, Historia e shtetit dhe e së drejtës në Shqipëri, 1994, S. 4-5; Justizministerium (Hrsg.), Ligja penale otomane, übersetzt ins Albanische von Dhimitër Kacimbra und. Koço Tasi, Tirana 1924.

6 Am 13. Mai 1913 wurde in Albanien der Kanun von Zhuria als erstes juristisches Dokument erlassen. Kanuni i Zhurisë (Jurisë), publiziert in der Zeitschrift, "Përlindja e Shqipnies", Vlora 1913, neu publiziert in: Jeta Juridike, Nr.1, 2007, S. 4 - 18.

7 Zakon o zastiti javne bezbednosti i poretka državi, Službeni list, Jahr III, br. 170 A., 3 August 1921.

8 Dodatak k Tumaču Krivičnog zakonika Kraljevine Jugoslavije, verfasst von Dolenc Metod, Zagreb, 1931.

9 Salihu, Ismet, Zhitija, Hilmi, Hasani, Fejzullah, Kodi Penal i Republikes së Kosovës. Komentar, Prishtina 2014, S. XXXII. 
angewendet wurde. Das erste Strafgesetzbuch der Föderativen Sozialistischen Republik Jugoslawien trat 1947 in $\mathrm{Kraft}^{10}$. Das damalige sowjetische Strafgesetzbuch war das Vorbild für das jugoslawische StGB. 1951 erging ein neues jugoslawisches StGB. ${ }^{11}$ Dabei orientierte man sich hauptsächlich am Vorbild des Strafgesetzbuches der Sowjetunion, aber auch am deutschen, österreichischen und schweizerischen Strafgesetz.

\subsection{DAS KOSOVARISCHE STRAFRECHT IN DER ZEIT VON 1974 BIS 1999}

Die Verfassung der Sozialistischen Föderativen Republik Jugoslawien (SFRJ) aus dem Jahre 1974 stellte die Autonome Provinz Kosovo den anderen Teilrepubliken rechtlich weitgehend gleich. ${ }^{12}$ Seit diesem Jahr wurde die Konzeption der Dezentralisierung der Zuständigkeiten auf die Ebene der acht Bundeseinheiten (Republiken und Autonome Provinzen) anerkannt. Gemäß Art. 281 Abs. 1 Ziffer 12 dieser Verfassung konnten alle Bundeseinheiten eigene Strafgesetze erlassen. Diesen Weg ist auch der Kosovo gegangen, der zum ersten Mal in der Geschichte ein eigenes Strafgesetz erließ, welches am 1. Juli 1977 in Kraft trat ${ }^{13}$. Am selbigen Tag trat auch das föderative Strafgesetz in $\mathrm{Kraft}^{14}$. Von diesem Zeitpunkt an waren auf dem Territorium des SFRJ acht Strafgesetze anwendbar. Das föderative StGB regelte schwerpunktmäßig den allgemeinen Teil des Strafrechts, während im besonderen Teil nur die Straftaten enthalten waren, bei denen es um den Schutz von Rechtsgütern ging, welche das ganze Jugoslawien betrafen, wie z.B. die Straftaten gegen die staatliche Rechtsordnung und Sicherheit, Hochverrat etc., sowie jene Sonderdelikte, die von Beamten der Gebietskörperschaften des Bundes begangen werden konnten. Im Übrigen regelten die Bundeseinheiten die Mehrzahl der Delikte des besonderen Teils bzw. sahen mehr Straftaten als das föderale StGB vor.

Das Strafgesetz von 1977 der Sozialistischen Autonomen Provinz Kosovo (SAPK) war bis zum 23. März 1989 in Kraft. An dem Tag hob das damalige serbische Regime verfassungswidrig die Autonomie des Kosovo auf. Diese Entwicklung führte auch zur Aufhebung des damaligen kosovarischen Strafgesetzes. Von 1989 bis zum Einrücken der NATO-Truppen am 10.06.1999 wurden im Kosovo parallel die serbischen und jugoslawischen Strafgesetze angewendet.

10 Krivični zakonik, 13. Dezember 1947, Belgrad, Broj 106, God. III, Službeni list FNRJ.

11 Krivični zakonik, 9. März 1951, Belgrad, Broj 13, God. VII, Službeni list FNRJ.

12 Ustav Socijalističke Federativne Republike Jugoslavije, Službeni list SFRJ, br. 9, Belgrad, 21.02.1974.

13 Krivični Zakonik Socijalističke Autonomne Pokrajine Kosovo, 1. Juli 1977.

14 Zakonika Krivičnom postupku Socijalističke Federativne Republike Jugoslavije, 14. Januar 1977, Službeni list SFRJ, br. 4, God. XXIII. 


\subsection{DAS KOSOVARISCHE STRAFRECHT VON DER BEFREIUNG DES KOSOVO 1999 BIS ZUM ERSTEN STGB 2004}

Nach der Befreiung des Kosovo und dem Einrücken der NATO-Truppen wurde der Kosovo unter das Protektorat der Mission der Vereinten Nationen im Kosovo (United Nations Interim Administration Mission in Kosovo, in der Folge: UNMIK) gestellt ${ }^{15}$. Art. 1 der Verordnung UNMIK/REG/1999/24 „On the Law applicable in Kosovo" vom 12.12.1999 erklärte diejenigen kosovarischen Gesetze, die am 22. März 1999 in Kraft waren und die nicht im Widerspruch zu den internationalen Standards standen, zum im Kosovo anwendbaren Recht. Artikel 3 der Resolution, ergänzt durch die Verordnung Nr. 2000/59 vom 27.10.2000, bestimmte, welches Recht im Kosovo anwendbar ist. Dabei erklärte Art. 1.1 lit. b UNMIK/REG/2000/59 grundsätzlich das vor dem 22.3.1989 im Kosovo geltende Recht für anwendbar. Aufgrund von Kritik der kosovarischen Rechtslehre und Rechtsprechung wurde durch den Sondergesandten des Generalsekretärs der UNO am 27.10.2000 eine neue Verordnung Nr. 2000/59 über das geltende Recht im Kosovo erlassen. Nach dieser Verordnung sollten weiterhin die alten jugoslawischen und kosovarischen Gesetze (auch Strafgesetze) in Kraft bleiben:

a. die durch den Sondergesandten des Generalsekretärs der Vereinten Nationen erlassenen Verordnungen und daneben andere Rechtsinstrumente, die diesen Verordnungen nicht widersprechen;

b. Gesetze, die vor dem 23.03.1989 in Kraft waren;

c. Gesetze des ehemaligen Jugoslawien und Serbiens von vor dem 23.03.1989, die nicht diskriminierend waren.

Wegen einer Rechtslücke wurde für den strafrechtlichen Bereich das alte kosovarische StGB (1977) für gültig erklärt bzw. wieder in Kraft gesetzt. Das erwähnte Strafgesetz sollte bis zum Erlass eines neuen Strafgesetzbuches für den Kosovo Geltung haben. Außerdem sollten das alte jugoslawische Strafgesetz (1977), die alte jugoslawische Strafprozessordnung von 1977 mit den Änderungen von 1985 sowie außerdem auch das serbische Strafgesetzbuch von 1977 und die Verordnungen der UNMIK neben anderen internationalen Menschenrechtsinstrumenten Anwendung finden.

Während dieser Zeit musste im Kosovo ein ganz neues Rechtssystem aufgebaut werden, wozu auch der Erlass neuer strafrechtlicher und strafverfahrensrechtlicher Gesetze zählte. Diese Erneuerung begann zunächst mit der Aufhebung der Todesstrafe. Sie wurde in Art. 1 der UNMIK-Verordnung 1999/24 aufgehoben. 2002 begann die Arbeit des Bewährungshilfedienstes im Kosovo. Mit der UNMIK-Verordnung 2003/25 wurde mit der Vorbereitung des neuen vorläufigen Strafgesetzbuches begonnen, im selben Jahr - aufgrund der UNMIK-Verordnung 2003/26 - auch mit dem Verfassen der neuen vorläufigen Strafprozessordnung. Die UNMIK-Verordnung 2004/8 regelte das Strafgesetz für Minderjährige als lex specialis. Bei der Kodifikation dieser Gesetze im strafrechtlichen Bereich arbeiteten über 30 einheimische und ausländische Strafrechtsexperten zusammen. Diese stammten zum Teil von der Organisation

15 Resolution Nr. 1991/1244 in der Sitzung 4011 am 10.06.1999. 
der Mission der Vereinten Nationen im Kosovo (UNMIK), der Amerikanischen Juristenvereinigung (American Bar Association, Central European and Eurasian Law Initiative: ABA/CEL, heute: ABA-ROLI), der Organisation für Sicherheit und Zusammenarbeit in Europa (OSZE), UNICEF sowie einzelnen anderen Organisationen aus Großbritannien und aus den USA.

Am Anfang hatte dieses „vorläufige“ Strafgesetzbuch das bosnische StGB als Vorbild. Danach wurden auch die Strafgesetze von Deutschland, Frankreich, Italien, der Schweiz und als Grundmodelle dazu genommen, sowie wurden die entsprechenden Bestimmungen der allgemeinen Rechtsgrundsätze der Strafgesetze von England und den USA berücksichtigt. ${ }^{16}$ Außerdem zog man eine große Zahl an Gesetzesbestimmungen von international relevanten Konventionen heran, deren hauptsächliches Ziel es war, den Schutz der Menschenrechte und Grundfreiheiten zu gewährleisten sowie die Kriminalität zu bekämpfen. Auch einige Grundsätze und konkrete Lösungen aus der Satzung des UNO-Tribunals in den Haag und des Römischen Statuts fanden Berücksichtigung.

\section{DIE VORLÄUFIGE STRAFRECHTSREFORM VOR DER UNABHÄNGIGKEITSERKLÄRUNG DES KOSOVO}

\subsection{DAS „VORLÄUFIGE“KOSOVARISCHE STGB 2004}

Das „vorläufige“ kosovarische StGB (im Folgenden: vorlStGB) wurde durch die UNMIK/VER/2003/25 am 6. April 2004 in Kraft gesetzt. Es wurde so genannt, weil der Kosovo während der Erarbeitung des vorlStGB kein selbstständiger Staat war. Nachdem der Kosovo am 17.02.2008 durch sein Parlament seine Unabhängigkeit erklärt hatte und am 15. Juni die Verfassung in Kraft getreten war, erließ der kosovarische Gesetzgeber am 6. November desselben Jahres das Gesetzes Nr. 03/1002 über die Vervollständigung und Änderung des vorlStGB. Seitdem wurde der Begriff ,vorläufig“ im Titel sowie im ganzen Text des damaligen StGB aufgehoben. Die installierte Rechtsordnung regelte nach Angaben des deutschen Diplomaten und UNO-Verwalters für den Kosovo, Michael Steiner, unter anderem den Umgang mit Terroristen, mit dem organisierten Verbrechen und mit Menschenschmuggel. ${ }^{17}$

Die wichtigsten Unterschiede des vorlStGB zu den alten Strafgesetzen im ehemaligen Jugoslawien waren einige Änderungen bezüglich der Sanktionen. In dieser Hinsicht sah das vorlStGB etliche alternative Maßnahmen als neue Sanktionen vor. Dazu gehörten folgende Regelungen: Betreuung durch den Bewährungsdienst, die Anordnung gemeinnütziger Arbeit und der Vollzug der Gefängnisstrafe mit Halbfreiheit. Außerdem wurde der Dienst für Bewährungshilfe vorgesehen. Es konnte auch die Strafe auf Bewährung (zur Probe) mit folgenden anderen Anordnungen kombiniert werden: der Anordnung der Betreuung durch den Bewährungsdienst, der Anordnung gemeinnütziger Arbeit und der Anordnung von Zwangsheilbehandlung.

16 Salihu, Ismet, Zhitija, Hilmi, Hasani, Fejzullah, Kommentar, Kodi Penal i Republikës së Kosovës, Prishtina 2014, S. VIII - (das Wort der Autoren).

17 Steiner, Michael, Ein neues Strafrecht für Kosovo, Neue Zürcher Zeitung, 7.7.2003. 


\subsection{DAS KOSOVARISCHE STRAFGESETZ FÜR MINDERJÄHRIGE 2004}

Mit der UNMIK-Verordnung 2004/8 wurde das Strafgesetz für Minderjährige als lex specialis geregelt. Dieses Gesetz vom 20. April 2004 ging von dem Grundsatz der Berücksichtigung der für das Wohlergehen des Minderjährigen besten Lösung aus. Dieser Grundsatz sollte bei jeder Verhängung einer Strafe oder Maßnahme berücksichtigt werden. Nach diesem Gesetz sollte die Freiheitsstrafe nur als ultima ratio verhängt werden. Wurde sie verhängt, dann sollte sie so kurz wie möglich sein.

Die Sanktionen und andere Maßnahmen nach diesem Gesetz waren: Diversionsmaßnahmen, Erziehungsmaßnahmen, die Anordnung der Leistung gemeinnütziger Arbeit und Gefängnisstrafe für Jugendliche. Grundsätzlich durfte keine Gefängnisstrafe unter sechs Monaten verhängt werden. Eine Haft durfte aber auch nicht mehr als maximal fünf Jahre betragen. Nur in besonders schwer wiegenden Fällen konnte eine Gefängnisstrafe in Höhe von bis zu zehn Jahren verhängt werden. Außerdem konnte gegen einen Minderjährigen im Falle der Begehung von zwei Straftaten eine Gefängnisstrafe von über zehn Jahren verhängt werden, unter der Bedingung, dass jede dieser Straftaten mit über zehn Jahren Freiheitsstrafe bestraft worden wäre.

\subsection{DIE „VORLÄUFIGE“ STRAFPROZESSORDNUNG 2004}

In der „vorläufigen“ StPO (im Folgenden: vorlStPO), welche durch UNMIK/ VER/2003/26 am 6. April 2004 in Kraft gesetzt wurde, war der wichtigste Fortschritt die Einführung der im Vergleich zum früheren Ermittlungsrichter größeren Rolle des Staatsanwaltes. ${ }^{18}$ Nach Sahiti, Murati und Elshani ${ }^{19}$ beinhalteten diese Vorschriften im Vergleich zum früheren Strafgesetz (1977) viele Lösungen in der Ermittlungsphase, die den internationalen Standards der Menschenrechte entsprachen.

\section{DIE STRAFRECHTSREFORM NACH DER UNABHÄNGIGKEITSERKL ÄRUNG DES KOSOVO}

\subsection{GERICHTSAUFBAU UND ZUSTÄNDIGKEIT DER GERICHTE IM KOSOVO}

Bevor ich auf die aktuelle kosovarische Strafrechtsreform eingehe, sollte ich mich der Verständlichkeit halber den kosovarischen Gerichtsaufbau und die Zuständigkeit der ordentlichen Gerichte vergegenwärtigen: Das Gerichtssystem des Kosovo baut auf den sieben regionalen Grundgerichten (erste Instanz), einem Berufungsgericht

18 Sahiti, Ejup, Murati, Rexhep, Elshani, Xhevdet: Kodi i Procedurës Penale, Komentar (GIZ), Prishtina 2014, S. 7. Prof. Sahiti und Prof. Murati fungierten als einheimische Experten bei der Erstellung der „,vorläufigen“ KStPO 2004.

19 Sahiti, Ejup, Murati, Rexhep, Elshani, Xhevdet, Kodi i Procedurës Penale, Komentar (GIZ), Prishtina 2014, S. 7. 
(zweite Instanz mit territorialer Jurisdiktion im ganzen Gebiet des Kosovo; Hauptsitz in Prishtina) und dem Obersten Gerichtshof als oberster Instanz für das ganze Gebiet des Kosovo auf. ${ }^{20}$

Die Grundgerichte sind in allen Angelegenheiten zuständig, wenn das Gesetz nichts anderes vorsieht ( $§ 17$ Abs. 1 Gesetz über Gerichte der Republik Kosovo, in der Folge: GVG). Sie sind auch für den Rechtsverkehr mit dem Ausland und die justizielle Zusammenarbeit in Strafsachen sowie für die Anerkennung und Vollstreckbarerklärung fremder Gerichtsurteile zuständig. Die Grundgerichte ( $§ 12$ Abs. 1 Ziffer $1-5 \mathrm{GVG}$ ) sind in folgende 5 Abteilungen gegliedert:
a. Allgemeine Abteilung
b. Abteilung für Handelssachen
c. Abteilung für Verwaltungsangelegenheiten
d. Abteilung für schwere Verbrechen und
e. Abteilung für Minderjährige.

In den Zuständigkeitsbereich des Strafrichters in Allgemeiner Abteilung fallen all jene Straftaten, die mit einer Geldstrafe bestraft werden und die keine Gefängnisstrafe über 10 Jahren nach sich ziehen. Bei Angelegenheiten der Abteilung für schwere Verbrechen (auch Strafrichter) - also für solche, die mit einer Gefängnisstrafe ab 10 Jahren bestraft werden - ist das Gericht mit drei Berufsrichtern besetzt. Für Verwaltungs- und Wirtschaftsangelegenheiten ist nur das Grundgericht in Prishtina zuständig; hier ist somit auch nur ein Einzelrichter zuständig. In die Zuständigkeit der Abteilung für schwere Verbrechen bei den Grundgerichten gehören laut § 15 GVG jene Straftaten, die in $\S 22$ StPO als schwere Straftaten aufgezählt sind.

$\S 18$ Abs. 1 Ziffer $1-4$ GVG regelt die Bestimmung der Zuständigkeit des Berufungsgerichts. Nach dieser Vorschrift entscheidet das Berufungsgericht in allen Rechtsmitteln gegen die Gerichte der ersten Instanz. Es ist aber auch in den anderen Angelegenheiten zuständig, die das Gesetz vorsieht. § $20 \mathrm{GVG}$ sieht fünf Abteilungen des Berufungsgerichts vor, die identisch mit den Abteilungen bei den Grundgerichten sind. Das Berufungsgericht besteht in allen Abteilungen immer aus einer Kammer von drei Berufsrichtern.

In $\S 21 \mathrm{GVG}$ ist die sachliche Zuständigkeit des kosovarischen obersten Gerichtshofs geregelt. Nach Abs. 1 ist er die oberste Gerichtsinstanz im Kosovo und besteht aus vier Sektionen, d.h. jeweils einer für Strafrecht, für Zivilrecht, für Verwaltungsrecht und für Gerichtspraxisangelegenheiten. In § $21 \mathrm{GVG}$ sind die Aufgaben des obersten Gerichts wie folgt definiert: Es entscheidet der OGH in letzter Instanz über (ordentliche und außerordentliche) Revisionen gegen Urteile der Berufungsgerichte); es bestimmt ferner die allgemeinen juristischen Grundsätze für die einheitliche Auslegung der Gesetze durch die Gerichte im Kosovo und die Angelegenheiten der kosovarischen Kammer für Eigentum. Am obersten Gericht entscheiden Senate aus drei Berufsrichtern, es sei denn, das Gesetz schreibt einen Spruchkörper aus mehr Richtern vor (§ 21 Abs. 6 GVG und $§ 51$ Abs. 2 JGG).

$20 \S 9$ Gesetz Nr. 03/L-199 über die Gerichte der Republik Kosovo, Gazeta Zyrtare Nr. 79/2010, einschließlich Gesetz Nr. 05/L-032 zur Änderung und Vervollständigung. 


\subsection{DAS KOSOVARISCHE STRAF-UND STRAFPROZESSRECHT NACH AKTUELLER GESETZESLAGE}

\section{a) Das aktuelle StGB}

Beim aktuellen Strafgesetzbuch des Kosovo (im Folgenden: StGB) ist maßgeblich, dass es im Einklang mit der Verfassung stehen muss. So bestimmt Art. 16 VerfKos, dass die Verfassung als oberster Rechtsakt in der Hierarchie steht. Gesetze und darunter stehende Verordnungen müssen im Einklang mit der Verfassung stehen ${ }^{21}$.

Gemäß $\S 1$ Abs. 1 des aktuellen StGB fallen unter dem Begriff der Straftat diejenigen Taten, bei denen es sich um eine Verletzung der Freiheiten und der Menschenrechte sowie eine Verletzung anderer Rechte und gesellschaftlicher Werte handelt, die durch die Verfassung und durch das internationale Recht geschützt werden. Der Schutz dieser Rechte und gesellschaftlicher Werte kann durch die strafrechtliche Gewalt realisiert werden.

Die außerordentliche Wichtigkeit der Verfassung für das kosovarische Strafrecht zeigt sich auch bei vielen anderen Rechtsvorschriften. Deutlich wird diese gravierende Bedeutung im Kapitel II, in dem unter anderem die Freiheits- und Grundrechte wie das Recht auf Leben, die Gleichheit vor dem Gesetz, die Bewegungsfreiheit und individuelle Privatrechte als von der Verfassung garantierte Grundfreiheiten vorgesehen sind. Im Einklang mit der Verfassung sanktionieren $\S \S 27$ und 28 StGB die Folter, barbarische, unmenschliche und erniedrigende Misshandlungen, die Sklaverei und die Zwangsarbeit als Straftaten.

Das aktuelle kosovarische Strafrecht ist gemäß Artikel 22 VerfKos verpflichtet, unmittelbar auch die folgenden internationalen Konventionen und Dokumente zu vollziehen:

1. Allgemeine Erklärung der Menschenrechte;

2. Europäische Menschenrechtskonvention (Konvention zum Schutze der Menschenrechte und Grundfreiheiten mit deren Protokollen);

3. Internationaler Pakt über bürgerliche und politische Rechte samt den Protokollen;

4. Rahmenkonvention des Europarats zum Schutz nationaler Minderheiten;

5. Internationales Abkommen zur Beseitigung jeder Form von Rassendiskriminierung;

6. Übereinkommen zur Beseitigung jeder Form von Diskriminierung der Frau;

7. Übereinkommen über die Rechte des Kindes;

8. Übereinkommen gegen Folter und andere grausame, unmenschliche oder erniedrigende Behandlung oder Strafe.

Diese Konventionen und Übereinkommen haben im Falle des Widerstreits mit den Gesetzen und anderen Verordnungen der kosovarischen Institutionen immer Vorrang. Das StGB sanktioniert in einem besonderen Kapitel (Kap. XV) 30 sog.

21 Zur kosovarischen Verfassung s. Küpper, Herbert: Die kosovarische Verfassungsordnung, JOR 49 (2008) S. 297-350. 
Straftaten gegen die Menschlichkeit und international geschützte Rechtsgüter kraft Völkerrechts.

Die Kontinuität des alten vorlStGB 2004 mit dem neuen StGB 2013 ist zu bejahen, denn im neuen StGB 2013 wurden 87 zusätzliche Paragraphen vorgesehen. Die wichtigsten Grundsätze des aktuellen StGB sind: staatliche Legalität des Strafrechts (§ 2 Abs. 1), welche durch die Sanktionen und Strafen manifestiert wird; Grundsatz der strafrechtlichen Verantwortung, welcher nach dem alten lateinischen Rechtsgrundsatz „nulla poena sine culpa“ ( 2 Abs. 2) im ganzen vorlStGB zugrunde gelegt wird. Nach dem o.g. Grundsatz der individuellen Verantwortlichkeit wird eine Person für eine von ihr begangene Straftat für schuldig erklärt, wenn in einem Strafverfahren festgestellt wird, dass sie bei Begehung der Tat verantwortlich und schuldfähig war. Ein anderer weiterer Grundsatz ist die gerichtliche Bestimmung der Strafe in Zusammenhang mit dem Grundsatz der Individualität, wonach die Art und das $\mathrm{Ma} ß$ der Strafen gegen den Täter von der Natur und der Schwere der Straftat sowie den individuellen Eigenschaften des Straftäters abhängig sind. Außerdem verbietet $\S$ 2 Abs. 3 StGB die Analogie, es sei denn zugunsten des Täters.

Es ist ferner erwähnenswert, dass nach $\S 6$ StGB 2013 die Vorschriften des allgemeinen Teils für alle Straftaten Geltung haben, die in Gesetzen der Republik Kosovo enthalten sind (also auch für das JGG und andere Gesetze). Nach diesem Paragraph wird festgestellt, dass es eine einheitliche Haltung des Staates in Bezug auf die grundlegenden Angelegenheiten der Kriminalpolitik gibt. Als Ausnahme von diesem erwähnten Grundsatz gelten die Fälle der sog. Lex posterior. Das ist z.B. der Fall in $\S 118$ StGB, nach dem für Minderjährige die besonderen Vorschriften des JGG gelten.

Das StGB ist in zwei Teile geteilt, den allgemeinen und den besonderen Teil, und seine detaillierten Regelungen umfassen 437 Paragraphen. Der allgemeine Teil des aktuellen StGB wird in den folgenden dreizehn Kapiteln und 120 Paragraphen detailliert geregelt.

Kapitel I: Allgemeine Vorschriften;

Kapitel II: Die Straftat und die Strafverantwortlichkeit;

Kapitel III: Die Strafen;

Kapitel IV: Der gerichtliche Verweis;

Kapitel V: Die Maßnahmen der Zwangsbehandlung;

Kapitel VI: Allgemeine Vorschriften für die Vollziehung der Strafen und die Befreiung mit Bewährung;

Kapitel VII: Die Beschlagnahme der Vermögenswerte des Täters durch seine begangene Straftat;

Kapitel VIII: Die Rechtsfolgen der Strafe;

Kapitel IX: Die Rehabilitation und Löschung der Daten aus dem Strafregister;

Kapitel X: Die Verjährung;

Kapitel XI: Die Begnadigung;

Kapitel XII: Die Anwendung des Strafgesetzes der Republik Kosovo nach dem Ort der begangenen Straftat;

Kapitel XIII: Die Bedeutung der Ausdrücke im StGB. 
Der allgemeine Teil des StGB umfasst ein System der strafrechtlichen Rechtsfolgen, mit denen die Angelegenheiten der Anwendung des besonderen Teils reguliert werden. So enthält der allgemeine Teil Regelungen z.B. zum Versuch, zur Fahrlässigkeit, zu den Arten von Strafen, zu Milderungs- oder Erschwerungsgründen der Strafe, zu den Arten der Strafbemessung, zur Möglichkeit der Befreiung von Strafe, zu den Strafausschließungsgründen, zur Verjährung und zur Rehabilitation. Hervorzuheben ist, dass die Vorschriften des allgemeinen Teils des StGB uneingeschränkt gelten, d.h. sie werden auf alle Tatbestände des besonderen Teils und andere Nebengesetze angewendet. Aus diesem Grund nennt man sie auch universelle Vorschriften.

Grundsätzlich kennt das aktuelle StGB des Kosovo Fälle, die, vereinfacht ausgedrückt, nach ihren Auswirkungen differenziert werden. Straftaten mit geringer Bedeutung gemäß $\S 11$ ff. StGB haben in der Regel keine Rechtsfolge für den Täter. Als schwere Straftaten gelten gemäß $§ 22$ StPO insgesamt 91 kodifizierte Straftaten. Dazwischen liegt der Bereich der „,mittleren Kriminalität“. Im gegebenen Zusammenhang sind insbesondere Straftaten der Kategorie „schwer“ i.S.v. § 22 StGB von Belang. Das kosovarische Strafgesetzbuch kennt eine Vielfalt von Körperverletzungsdelikten, die wie folgt abgestuft werden: leichte Körperverletzung, fahrlässige schwere Körperverletzung, schwere Körperverletzung im Affekt, schwere Körperverletzung, schwere Körperverletzung mit tödlichem Ausgang

An dieser Stelle ist zu betonen, dass das aktuelle StGB entgegen der allgemeinen Erwartung nicht alle aufgeführten Tatbestände des vorlStGB (2004) übernommen hat. Dies betrifft Straftatbestände im Bereich der fahrlässigen schweren Körperverletzung ( $\$ 154$ Abs. 5 vorlStGB a.F.), der schweren Körperverletzung im Affekt ( $\$ 154$ Abs. 6 a.F.) und der schweren Körperverletzung mit tödlichem Ausgang ( $\$ 154$ Abs. 4 vorlStGB a.F.). Zu Recht behauptet Ismet Salihu, Professor für Strafrecht an der Rechtswissenschaftlichen Fakultät der Universität Pristina (nun: „Hasan Prishtina“-Universität), dass im Zuge der Aufnahme der Tatbestände in das neue Strafgesetzbuch möglicherweise unverzeihliche technische Fehler unterlaufen sein könnten. Andernfalls ließe sich keine Erklärung für diese Entscheidung finden, würden diese Straftaten doch alltäglich begangen. Deshalb sei es verwunderlich, dass die kosovarische Justiz ohne diese grundlegenden Bestimmungen der Strafverfolgung ordnungsgemäß nachgehen kann. Salihu fordert die Beachtung dieser Tatbestände nach der alten Form des vorlStGB (2004).

Eine wesentliche Komplikation des StGB (2012) ist das fehlende Grunddelikt der fahrlässigen Körperverletzung. Während in vielen besonderen Delikten auch die fahrlässige Begehung einer Körperverletzung mit Strafe bedroht wird, wurde kein entsprechendes klares Grunddelikt, wie es in der alten Fassung des vorlStGB (2004) bestand, in das neue StGB aufgenommen. Im StGB (2003) war in § 154 Abs. 5 die fahrlässige Herbeiführung einer schweren Körperverletzung ein strafbarer Tatbestand, welcher als das entsprechende Fahrlässigkeitsdelikt der vorsätzlichen schweren Körperverletzung in $\S 154$ Abs. 1 vorlStGB (2004) normiert gewesen ist. In der n.F. des StGB finden sich im Kapitel XVI ausschließlich vorsätzliche Körperverletzungen. Strafdelikte gegen Leib und Leben sind ausdrücklich vorgesehen. 
Die fahrlässige Tötung gemäß § 181 StGB (2012) wurde hingegen selbstverständlich als Fahrlässigkeitsvariante zur vorsätzlichen einfachen Tötung gemäß § 178 StGB (2012) und schweren Tötung (Mord) gemäß § 179 StGB (2012) normiert.

Die (vermeintlich) fehlende eindeutige Kriminalisierung der fahrlässigen schweren Körperverletzung führt zu gravierenden Missverständnissen in der Lehre und insbesondere in der Rechtspraxis. Es ist nicht verständlich, weshalb in verschiedenen speziellen Delikten eine fahrlässige schwere bzw. sogar leichte Körperverletzung bestraft wird, im aktuellen StGB das aber nicht verständlicher konkretisiert wurde und die Möglichkeit unterschiedlicher Interpretationen besteht. Da z.B. fahrlässige schwere Körperverletzungen im Leben erfahrungsgemäß sehr oft vorkommen und es sich hierbei nicht um ein Bagatelldelikt handelt, erscheint das Ausbleiben einer Strafe unverhältnismäßig und nicht gerechtfertigt.

Beispielsweise wird nach $\S 378$ StGB (2012) als Gefährdung im Straßenverkehr die fahrlässige Verursachung von Körperverletzungen nach Abs. 1 und Abs. 2 i.V.m. Abs. 6 mit Geldstrafe oder mit Gefängnisstrafe von bis zu einem Jahr sanktioniert. Nach diesem Delikt kann auch eine leichte Körperverletzung als Folge der Gefährdung der Sicherheit im Straßenverkehr bestraft werden ${ }^{22}$.

Die fahrlässige Herbeiführung einer schweren Körperverletzung steht auch gemäß § 176 Abs. 1 und 3 StGB (2012) unter Strafe, wie auch der illegale Besitz, die Verwendung, Beförderung und Lagerung von nuklearem Material. Ebenso wird die fahrlässige Verursachung einer schweren Körperverletzung beispielsweise nach § 255 Abs. 3 StGB (2012) bei der Verbreitung von ansteckenden Krankheiten und nach $\S$ 259 Abs. 2 StGB bei der Einstellung eines ansteckend schwerkranken Arbeitnehmers bestraft.

Die fahrlässige Herbeiführung von Körperverletzungen wird regelmäßig als Erfolgsqualifikation innerhalb verschiedener Delikte des StGB (2012) normiert. Umso unverständlicher ist daher, weshalb es kein Grunddelikt der fahrlässigen schweren Körperverletzung im StGB n.F. geben soll. In der Praxis gibt es viele fahrlässige schwere Körperverletzungen. Daher besteht die Frage, wie in der Rechtspraxis fahrlässige Handlungen mit einem erheblichen sozialen Störwert sanktioniert werden können.

\section{b) Die strafrechtlichen Sanktionen und Maßregeln der Sicherung und Besserung}

Nach dem kosovarischen Strafrecht steht es einzig und allein dem Staate zu, eine Person aufgrund einer begangenen Straftat zu bestrafen. Nach diesem Grundsatz wird jeder Täter von Amts wegen verfolgt. Im allgemeinen Teil des StGB sind strafrechtliche Sanktionen und Maßregeln der Sicherung und Besserung (Maßnahmen der obligatorischen Behandlung) vorgesehen: Die Strafen nach $\S 4$ Abs. 1 des StGB sind Hauptstrafen ( $\$ 43 \mathrm{StGB}$ ), alternative Strafen ( $49 \mathrm{StGB})$, Nebenstrafen ( 62 StGB) und gerichtliche Verweise ( $885 \mathrm{StGB})$.

aa) Hauptstrafen. Hauptstrafen (Primärstrafen) nach $\S 43$ StGB sind jene Strafen, die das Gesetz als hauptsächliche Maßnahmen der Bestrafung vorsieht. In

$22 \mathrm{Zu}$ vergleichbaren Problemen im slowenischen Recht s. Ambrož, Matjaž, Der Besondere Teil des neuen slowenischen Strafgesetzbuchs, JOR 51 (2010) S. 319-332. 
den $\S \S 43 \mathrm{ff}$. StGB sind folgende Hauptstrafen vorgesehen:

- lebenslängliche Gefängnisstrafe (Freiheitsstrafe);

- Gefängnisstrafe (Freiheitsstrafe);

- Geldstrafe.

Gemäß § 44 Abs. 1 - 3 StGB ist eine lebenslängliche Gefängnisstrafe für die schwersten Straftaten auszusprechen. Unter besonders schweren Umständen und schweren Folgen werden die Straftaten verstanden, für die vormals im vorlStGB 2004 die Todesstrafe galt. Die lebenslängliche Gefängnisstrafe ist nicht als einzige Hauptstrafe für eine einzelne Straftat vorgesehen (gem $\S 44$ Abs 2 StGB wird die lebenslängliche Gefängnisstrafe als alternative Strafe zu einer Gefängnisstrafe vorgesehen), und sie kann gegenüber einer Person unter 21 Jahren oder bei verminderter Schuldfähigkeit des Täters zum Zeitpunkt der Begehung der Tat nicht ausgesprochen werden ( $§ 44 \mathrm{Abs} 3 \mathrm{StGB})$.

$\S 45$ Abs. 1 - 2 StGB bestimmt, dass eine Gefängnisstrafe nicht unter 30 Tagen und nicht über 25 Jahren verhängt werden kann. Sie wird in vollen Jahren und im Falle einer Strafe von bis zu sechs Monaten in vollen Tagen verhängt.

Die Geldstrafe ist für keine Straftat des aktuellen StGB als alleinige Hauptstrafe vorgesehen, vielmehr ist sie immer eine Alternative zur Freiheitsstrafe. ${ }^{23}$ Gemäß $\S 46$ Abs. 1 - 6 StGB sind Geldstrafen in der Regel über einen Betrag von nicht weniger als 100,- $€$ und maximal 25.000,- $€$ zu verhängen, es sei denn, es handelt sich um Straftaten aus den Bereichen Terrorismus, Menschenhandel, organisiertes Verbrechen oder um andere Straftaten, die mit der Absicht der rechtswidrigen Zueignung von Vermögen begangen wurden. Diese Straftaten können mit einer Geldstrafe von bis zu 500.000,- $€$ bestraft werden. Wenn der Täter die Geldstrafe nicht zahlen will oder kann, dann kann das Gericht sie durch eine Gefängnisstrafe ersetzen. In diesem Falle wird ein Tag im Gefängnis mit 20,- $€$ berechnet, und es kann eine Strafe von maximal drei Jahren Gefängnis verhängt werden. Sie kann alternativ gemeinsam mit einer Freiheitsstrafe als Hauptstrafe und als Nebenstrafe ausgesprochen werden. Bei den Freiheitsstrafen in einer Höhe von bis zu sechs Monaten kann das Gericht mit Zustimmung des Bestraften die Freiheitsstrafe durch eine Geldstrafe ersetzen ( $§ 47$ StGB) oder anstelle der Freiheitsstrafe gemeinnützige Arbeit anordnen ( $\$ 48 \mathrm{StGB}$ ).

bb) Alternative Strafen ( $\$ 49$ StGB). Nach Rexhep Gashi, Professor für Kriminologie an der Rechtswissenschaftlichen Fakultät in Prishtina, sind unter den Alternativen zur Freiheitsstrafe, ,jene Maßnahmen und Strafen zu verstehen, durch die vermieden werden kann, die Straftäter in Besserungsanstalten zu überstellen" ${ }^{24}$. In $\S$ 49 StGB sind folgende alternative Strafen vorgesehen: Verurteilung zur Bewährung, Freigang und Bewährungsstrafe mit Anordnung gemeinnütziger Arbeit. Nach § 49 Abs. 2 StGB kann das Gericht bei Verhängung einer Bewährungsstrafe auch die Anordnung einer verpflichtenden Rehabilitationsmaßnahme oder die Anordnung der Beaufsichtigung durch den Bewährungsdienst aussprechen.

cc) Nebenstrafen. Nebenstrafen ( $\$ 62 \mathrm{StGB}$ ) sind von sekundärem Charakter; sie

23 Salihu, Ismet, Zhitija, Hilmi, Hasani, Fejzullah, Kommentar. Kodi Penal i Republikës së Kosovës, Prishtina 2014, S. 193.

24 Gashi, Rexhep, Ekzekutimi i denimeve alternative, Prishtina 2013, S. 17. 
können ergänzend zur Hauptstrafe oder auch alternativ verhängt werden. Gemeinsam mit der Hauptstrafe oder alternativ dazu können folgende Nebenstrafen ausgesprochen werden: Geldstrafe, Entzug des Wahlrechts, Anordnung der Entschädigung des Verlusts oder Schadens, Verbot der Ausübung öffentlicher Ämter, Berufsverbot, Entzug der Fahrerlaubnis, Beschlagnahme, Anordnung der Veröffentlichung des Urteils und Ausweisung eines Ausländers aus dem Kosovo.

dd) Gerichtliche Verweise ( $\$ 85$ StGB). Ihre Zielsetzung ist es, einem Straftäter das Übel seiner Tat zu verdeutlichen, wobei sämtliche Begleitumstände in Bezug auf die Tat und auf den Täter berücksichtigt werden und der Verweis ausreichend sein muss, um das Strafziel zu erreichen.

ee) Schuldspruch ohne Strafe. Eine Besonderheit im kosovarischen Strafrecht stellt auch der sog. Schuldspruch ohne Strafe nach $\S 78$ StGB dar. So besteht die Möglichkeit eines Schuldspruches ohne Strafe ${ }^{25}$, bei welchem die Belastung des Täters durch die Tatfolgen, u.a. auch bei fahrlässiger Tötung eines Angehörigen, berücksichtigt wird. Wenn der Täter durch die Tat und ihre Folgen psychisch derart schwer belastet ist, erscheint eine Bestrafung verfehlt (naturalis poena). In der kosovarischen Rechtspraxis wird eine psychische Belastung nur bei Verletzung von Familienangehörigen angenommen. So wie in Deutschland erfolgt auch im Kosovo ein Schuldspruch durch das Gericht, allerdings kann von einer Bestrafung abgesehen werden.

\section{c) Besonderer Teil}

Der besondere Teil ( $\S 121$ bis 437) des StGB ist in 21 Kapiteln nach dem geschützten Rechtsgut systematisiert. Dort sind die einzelnen Tatbestände detailliert unterteilt. Die einzelnen Delikte sind dabei den folgenden Kapiteln zugeordnet:

Kapitel XIV: Straftaten gegen die Verfassungsordnung und die Sicherheit der Republik Kosovo;

Kapitel XV: Straftaten gegen die Menschlichkeit und die von internationalem Recht geschützten Rechtsgüter;

Kapitel XVI: Straftaten gegen Leib und Leben;

Kapitel XVII: Straftaten gegen die Freiheit und Menschenrechte;

Kapitel XVIII: Straftaten gegen die Wahlrechte;

Kapitel XIX: Straftaten gegen die Rechte aus Arbeitsverhältnissen;

Kapitel XX: Straftaten gegen die sexuelle Integrität;

Kapitel XXI: Straftaten gegen die Ehe und die Familie;

Kapitel XXII: Straftaten gegen die öffentliche Gesundheit;

Kapitel XXIII: Straftaten im Zusammenhang mit Drogen;

Kapitel XXIV: Organisierte Kriminalität;

Kapitel XXV: Straftaten gegen die Wirtschaft;

Kapitel XXVI: Straftaten gegen öffentliche Dienstleistungen;

Kapitel XXVII: Straftaten gegen das Eigentum;

Kapitel XXVIII: Straftaten gegen die Umwelt, Tiere, Pflanzen und Kulturgüter;

25 Ähnlich $§ 60$ deutsches StGB: Schuldspruch ohne Strafe. 
Kapitel XXIX: Straftaten gegen die allgemeine Sicherheit der Personen und des Eigentums;

Kapitel XXX: Straftaten im Zusammenhang mit dem Umgang mit Waffen, Munition oder explosionsgefährlichen Stoffen;

Kapitel XXXI: Straftaten gegen die Sicherheit des öffentlichen Verkehrs;

Kapitel XXXII: Straftaten gegen die Führung der Judikative und öffentlichen Verwaltung;

Kapitel XXXIII: Straftaten gegen die öffentliche Ordnung;

Kapitel XXXIV: Amtskorruption und Straftaten gegen das Beamtenrecht.

\section{d) Prozessordnung}

Die Primärquelle des Strafprozessrechts im Kosovo ist die Strafprozessordnung (in der Folge: StPO). Die aktuelle kosovarische Strafprozessordnung trat am 1. Januar 2013 in Kraft. Die qualitativen und umfangreichen Vervollständigungen und Änderungen in dieser StPO stellen sich als eine neue Regulierung der Strafprozessordnung des Kosovo dar.

Der Maßstab der verfassungskonformen Auslegung gilt nicht nur im materiellen Recht, sondern auch in der Strafprozessordnung. Dies geht am deutlichsten aus $\S$ 3 Abs. 2 StPO hervor. Diese Vorschrift inkorporiert den verfassungsrechtlichen Grundsatz der Unschuldsvermutung. In diesem Paragraph wird klargestellt, dass sich jeder Zweifel hinsichtlich der Tatsachen in der Sache oder in der Vollziehung einer Vorschrift des Strafgesetzes zu Gunsten des Beschuldigten und seiner Rechte auswirken muss.

Das Strafverfahrensrecht wird bei jeder Person angewendet, welche nach dem materiellen Strafrecht ( $\S 114-118$ StGB) für eine Straftat verantwortlich ist. Die Immunität der Mitglieder der staatlichen Institutionen wird durch die Verfassung und durch spezielle Gesetze geregelt. Bei ausländischen Personen, die Immunität genießen, finden die Normen des internationalen Rechts unmittelbare Anwendung ( $§$ 492 Abs. 1 StPO).

Durch die aktuelle StPO 2013 wurden viele neue Vorschriften gegenüber der vorlStPO2004 eingeführt. Zwei wichtige Komponenten sind in $\S 1$ Abs. 2 und 3 derneuen StPO niedergelegt. Dabei handelt es sich auf der einen Seite um den größtmöglichen Schutz der Gesellschaft vor Kriminalität und auf der anderen Seite um den Schutz der Menschenrechte und Grundfreiheiten der verdächtigten Person. Im Unterschied zu der vorläufigen StPO, welche dem Akkusationsprinzip (Anklagegrundsatz) folgte, orientiert sich die neue StPO an einem gemischten Akkusationsprinzip. In diesem Zusammenhang muss gesagt werden, dass auch das Gericht bei der Beweisaufnahme tätig sein kann. Aufgrund der aktuellen StPO kann die Anklage nach dem Grundsatz nemo iudex sine actore nur die Staatsanwaltschaft erheben ( $\$ 6$ Abs. 2 und 3 StPO). Nach den neuen Regelungen existieren keine privaten und subsidiären Ankläger mehr. Aufgrund dessen wird im kosovarischen Strafverfahren die Anklage nur durch die Staatsanwaltschaft erhoben und in der Sitzung vom Staatsanwalt vertreten. Dieses Prinzip ist geprägt von der Idee der Gewaltenteilung und von der Auffassung, dass die Justiz unabhängig sein muss. Der Anklagegrundsatz nach der StPO bedeutet, 
dass nur Taten gerichtlich verfolgt werden dürfen, wenn dies von einem berechtigten Ankläger, wie in diesem Fall einem Staatsanwalt, verlangt wird. Nach § 52 StPO ist der Staatsanwaltschaft auch die Möglichkeit eingeräumt, sich aus dem Strafverfahren zurückzuziehen. In diesem Fall muss das Gericht abhängig von der Entwicklungsphase des Verfahrens das Strafverfahren mit Beschluss einstellen oder durch Gerichtsurteil die Anklage abweisen. Es besteht jedoch gemäß $§ 79$ StPO die Pflicht für jeden kosovarischen Bürger, neu begangene Straftaten zur Anzeige zu bringen.

Es bestehen die zwei folgenden Ausnahmen vom Legalitätsprinzip:

- die Fälle, in denen für das Einleiten des Verfahrens der Antrag des Geschädigten, der Vorschlag des Geschädigten oder eine vorherige Zustimmung der zuständigen Behörde benötigt wird;

- die Fälle, in denen die Staatsanwaltschaft auf der Basis des Grundsatzes der Zumutbarkeit berücksichtigt, ob sie das Strafverfahren einstellt (liegt kein hinreichender Tatverdacht vor stellt die Staatsanwaltschaft das Ermittlungsverfahren ein) oder das Strafverfahren verzichtet (auf Grund der Verfahrenshindernissen) bzw. in denen sie nach dem Opportunitätsprinzip nicht verpflichtet ist, ein Strafverfahren einzuleiten.

Es gab auch ältere Vorschriften, die in die neue StPO nicht übernommen wurden. Dazu gehören z.B. die Bestätigung der Anklage sowie die Verfahren hinsichtlich der internationalen Rechtshilfe und der Vollziehung internationaler Vereinbarungen in Strafsachen. Im Gegenzug wurden in die StPO Vorschriften über Strafverfahren aufgenommen, in denen die Straftat durch seelisch kranke Personen begangen wurde. Außerdem wurde zum ersten Mal das Rechtsinstitut der Diversion im Erwachsenenstrafrecht vorgesehen ( $§ 184$ StPO). Dieses Rechtsinstitut ist nicht nur Teil einer größeren Anzahl von nicht klassischen Strafen und diversionellen Sanktionen des Strafrechtssystems, sondern auch eine von insgesamt neun Sicherungsmaßnahmen für die Anwesenheit des Angeklagten im Strafverfahren ( $\$ 173 \mathrm{StPO}$ ). Außerdem wurde auch die strafrechtliche Mediation, die bereits in der vorläufigen StPO 2004 vorgesehen war, in die aktuelle Strafprozessordnung übernommen (§ $232 \mathrm{StPO}$ ). Sie ist ein Rechtsinstitut der so genannten alternativen Verfahren i.S.d. §§ 229-233 StPO.

Hervorzuheben ist, dass nach Meinung von Sahiti / Murati / Elshani die neu in Kraft getretenen Vorschriften, die in der StPO 2013 aus 22 Strafprozessordnungen anderer Staaten übernommen wurden, den Einflüssen des angelsächsischen Strafverfahrens unterliegen.

Es lässt sich feststellen, dass die aktuelle StPO die folgenden Prinzipien beinhaltet:

1. das Offizialprinzip der Strafverfolgung ( $77 \mathrm{StPO})$;

2. das Legalitätsprinzip der Strafverfolgung ( $(6$ Abs. 2 und 3 StPO);

3. das Akkusationsprinzip ( $\S \S 6$ und $52 \mathrm{StPO}$ );

4. ne bis in idem ( $\$ 6 \mathrm{StPO})$;

5. die Unschuldsvermutung ( 33 Abs. 1 StPO);

6. die Untersuchungsmaxime: Suche nach der objektiven Wahrheit ( $\S 1,7$, 288 Abs. 2, 329 Abs. 4 StPO); 
7. fair trial / das Recht auf ein faires Verfahren gemäß Art. 6 EMRK;

8. den Grundsatz der Unmittelbarkeit (unmittelbare Beweisaufnahme: $\S \S 123$ Abs. 4 und 361 Abs. 2 StPO);

9. das Mündlichkeitsprinzip (rechtliches Gehör und Mündlichkeit in der Strafverhandlung; der Angeklagte hat das Recht, dass in einer ihm verständlichen Sprache verhandelt wird: Art. 21 VerfKos, $\S \S 14$ und 21 StPO);

10. die rechtmäßige Verurteilung innerhalb einer angemessenen Zeit ( $55 \mathrm{StPO})$;

11. im Zweifel für den Angeklagten (in dubio pro reo: $\S \S 2,3$ Abs. 2 und $\S 7$ StPO);

12. den Öffentlichkeitsgrundsatz (Art. 31 VerfKos, § 7 GVG, § 10 StAG; §§ 245, 254, 293, 366, 390 Abs. 5, 407 Abs. 1 StPO);

13. den Grundsatz der prozessualen Waffengleichheit;

14. denÖkonomie-undBeschleunigungsgrundsatz, denEntschädigungsgrundsatz und den der Rehabilitation ( $§ 15 \mathrm{StPO}$ ).

Nach diesen Prinzipien des Strafverfahrens lässt sich feststellen, dass die normativen Aspekte der aktuellen StPO im Einklang mit den internationalen Menschenrechtsstandards unter Achtung der Menschenrechte und Grundfreiheiten aufgebaut sind. In Gestalt der o.g. Prinzipien wurden ferner dem Staat vorgegebene Grundrechte sowie das Legalitätsprinzip umgesetzt. Nach dem Legalitätsprinzip, das in $\S 6$ Abs. 1 und 2 StPO normiert ist, gilt ein Verfolgungs- und Anklagezwang. Es besteht die Verpflichtung der Staatsanwaltschaft, bei Vorliegen eines Anfangsverdachtes Ermittlungen durchzuführen und Anklage zu erheben.

In $\S 3$ Abs. 1 StPO wird die Unschuldsvermutung garantiert. Dieser Paragraph enthält folgende Definition: ,Jede Person, die einer Straftat angeklagt ist, gilt bis zum gesetzlichen Beweis ihrer Schuld als unschuldig." Nach diesem Grundsatz gilt jeder Beschuldigte bis zu seiner Verurteilung als unschuldig.

Der Grundsatz in dubio pro reo wurde in $\S 2$, $\S 3$ Abs. 2 und $\S 7$ StPO niedergelegt. Nach diesem Grundsatz muss das Gericht im Zweifel bei der Feststellung von Tatsachen stets zugunsten des Angeklagten entscheiden. Folglich ist der Angeklagte freizusprechen, wenn nicht mit an Sicherheit grenzender Wahrscheinlichkeit seine Schuld bewiesen wird.

Auch dem demokratischen Prinzip wurde durch den Grundsatz der Öffentlichkeit des Verfahrens, das rechtliche Gehör und die Mündlichkeit in der Strafverhandlung sowie die Mitwirkung des Volkes an der Strafjustiz im Rahmen der kosovarischen Gerichte Rechnung getragen. Gemäß $\S 14$ StPO sind Verfahrenshandlungen in albanischer und serbischer Sprache vorzunehmen, da diese nach Art. 6 VerfKos die Staatsprachen sind. Erweitert wird dieser Grundsatz durch Sonderregelungen für bestimmte Volksgruppen.

Hervorzuheben ist die Untersuchungsmaxime: Die Suche nach der objektiven Wahrheit ( $\S 1,7,288$ Abs. 2, 329 Abs. 4 StPO) ist im kosovarischen Strafprozessrecht in $\S 7$ StPO geregelt, wo die Aufgaben der Staatsanwaltschaft und des Gerichts bestimmt sind. Nach diesem Paragraphen sind die Staatsanwaltschaft und die Gerichte 
zur Aufnahme aller Beweise verpflichtet, die sowohl gegen den Verdächtigen bzw. Angeklagten als auch zu seinen Gunsten sprechen. Im Weiteren obliegt es gemäß $\S 288$ Abs. 2 StPO dem Gerichtsvorsitzenden, alle erforderlichen Maßnahmen zu ergreifen, um über die Strafsache rechtmäßig zu entscheiden. Nach diesem Grundsatz haben also Polizei, Staatsanwaltschaft und Gericht die Pflicht, mit allen rechtlich zur Verfügung stehenden Mitteln die Wahrheit zu erforschen. Eine Ausnahme von diesem Grundsatz stellt der Fall einer Beweisaufnahme dar, die gegen gesetzliche Beweisverbote verstieße (§ 249 Abs. 4, § 259 Abs. 1-2, § 348 Abs. 1 Nr. 8, § 338 Abs. 2 StPO). Nach diesem Grundsatz kann die Strafverfolgungsbehörde bei der Ausübung ihrer Befugnisse und bei der Aufnahme von Beweisen nur so weit in die Rechte von Personen eingreifen, als dies gesetzlich zulässig ist. Entsprechend gilt ein Gerichtsurteil, welches aufgrund von unzulässig erhobenen Beweisen zustande gekommen ist, als nichtig. Deshalb ist das Gericht nach § $361 \mathrm{Abs} .2$ StPO verpflichtet, jeden Beweis sowohl einzeln als auch in Zusammenhang mit anderen Beweisen zu bewerten und zusammenfassend zu beurteilen.

Der Grundsatz der prozessualen Waffengleichheit wurde nicht speziell in der StPO geregelt, jedoch wird er in vielen Phasen des Strafverfahrens praktiziert. So ist z.B. nach Sahiti / Murati gemäß $§ 10$ StPO der Verdächtige schon bei der ersten Vernehmung in seiner Sprache über die Gründe und die Art des Tatverdachts zu informieren; im Weiteren bestimmt gemäß $§ 188$ Abs. 1 StPO der Untersuchungsrichter im Falle der Verhängung der Untersuchungshaft die Anhörungsverhandlung; nach Einreichung der Anklage bei Gericht berät das Gericht in der ersten und in der zweiten Verhandlung über die Anklageschrift sowie über die Zulassung der Beweismittel ( $\S$ 242, 245 und 254 StPO). In der Hauptverhandlung wird der Grundsatz der prozessualen Waffengleichheit am umfassendsten realisiert. So wird nach der Verlesung der Anklageschrift dem Angeklagten das Wort gegeben. Von ihm wird verlangt, sich schuldig oder nicht schuldig zu bekennen. Der Angeklagte kann sich verteidigen, indem er die zugelassene Anklage einer rechtlichen Bewertung unterzieht. Besonders wird dieser Grundsatz in $\S 9$ Abs. 2 StPO betont. Nach dieser Vorschrift steht es den Konfliktparteien zu, Zeugen und Gutachter - sowohl die eigenen als auch die der gegnerischen Partei - zu befragen. Am Ende der Verhandlung hat jede Konfliktpartei nochmals die Möglichkeit, sich zu äußern. Ist ein Rechtsmittel gegen ein Urteil der ersten Instanz eingelegt, muss zuerst der vorsitzende Richter der ersten Instanz vor Einreichung dieser Beschwerde bei der zweiten Instanz eine Kopie der Berufung der anderen Partei zusenden, welche sich zu dieser Berufung schriftlich äußern kann.

Der kosovarische Staat hat gemäß $§ 15$ StPO den Schaden, den eine Person durch eine zu Unrecht erlittene Festnahme oder Haft erlitten hat, zu ersetzen. Über die Entschädigung wird ein besonderes Verwaltungs- oder Gerichtsverfahren auf Antrag des Betroffenen gemäß $§ 526 \mathrm{StPO}$ durchgeführt.

Das kosovarische Strafverfahren nach $\S 68$ StPO gliedert sich in folgende drei Stadien:

- Vor der Anklagerhebung:

- Ermittlungsverfahren,

- Anklageerhebung gegen den Beschuldigten (Anklageerhebung und 
Überprüfung der Anklage bzw. der Erklärung des Beschuldigten);

- Hauptverfahren:

- Vorbereitung der Hauptverhandlung,

- Hauptverhandlung,

- Urteilsentscheidung und Verkündung;

- Rechtsmittelverfahren.

Das kosovarische Strafverfahren kennt drei Grundformen des Strafverfahrens in erster Instanz:

- ordentliches (reguläres) Strafverfahren,

- alternatives Strafverfahren und

- Jugendstrafverfahren

Das ordentliche (reguläre) Strafverfahren wird als volles Strafverfahren bezeichnet, welches alle Stadien durchlaufen kann. Das alternative Verfahren ist kürzer und umfasst nicht alle Stadien des Strafverfahrens. Das Jugendstrafverfahren hat einige Besonderheiten, weshalb es als besonderes Strafverfahren bezeichnet wird.

Die bereits angesprochenen alternativen Verfahren, die in Kapitel XXVI der vorläufigen StPO 2004 als Aussetzung bzw. Einstellung des Verfahrens oder Verzicht auf die Verfolgung von kleinen Straftaten kodifiziert waren, und die strafrechtliche Mediation als Tatausgleich, die in Kapitel XXVII der alten StPO vorgesehen $w a r,{ }^{26}$ sind nun in Kapitel XIV der neuen StPO (2013) als alternative Verfahren aufgenommen. So kann die Staatsanwaltschaft nach $\S 229$ StPO die alternativen Verfahren oder die Diversion gemäß $\S 184$ StPO (welche kein alternatives Verfahren i.S.d. StPO ist) anwenden, soweit dies in ihre Zuständigkeit gemäß § 49 StPO fällt. Voraussetzung für eine Diversion nach $\S 184 \mathrm{StPO}$ ist im Besonderen, dass die begangene Straftat mit einer Gefängnisstrafe von nicht mehr als einem Jahr bedroht ist. $\mathrm{Zu}$ den weiteren Voraussetzungen gehört, dass dem Beschuldigten nicht schon einmal eine Diversionsmaßnahme gewährt wurde bzw. dass er nicht schon einmal verurteilt worden ist. Ferner muss der Staatsanwalt dem Vorschlag des Ermittlungsrichters zu einer Diversion zustimmen bzw. muss der Staatsanwalt eine Diversion selbst vorschlagen.

Die Staatsanwaltschaft kann die alternative Maßnahme gemäß $\S 230$ StPO anwenden und vorübergehend das Verfahren aussetzen, d.h. vorläufig auf die Verfolgung der Straftat verzichten, wenn die begangene Straftat nur mit Geldstrafe oder mit einer Gefängnisstrafe bedroht ist, deren Höchstmaß drei Jahre nicht übersteigt, und der Beschuldigte die von der Staatsanwaltschaft vorgeschlagenen Verpflichtungen erfüllt.

Gemäß $§ 231$ StPO ist der Staatsanwalt nicht verpflichtet, das Strafverfahren einzuleiten, und kann von der Verfolgung absehen,

a. wenn das Gesetz vorsieht, dass das Gericht von der Strafe absehen kann,

26 In der alten StPO (der so genannten ,vorläufigen Strafprozessordnung Kosovos“ 2004) war das kurze Verfahren für die Straftaten, die mit einer Geld- oder einer Freiheitsstrafe von bis zu 3 Jahren bedroht waren, vorgesehen. Als Voraussetzung der Anwendung eines kurzen Verfahrens galt, dass die Straftat nur eine geringe Gefährdung der Allgemeinheit darstellte. 
und der Staatsanwalt aufgrund der Sachlage zu dem Schluss gelangt, dass nicht einmal ein Schuldspruch ohne Strafe notwendig erscheint, oder

b. wenn der Täter seine Straftat ehrlich bereut und die Folgen der Straftat wiedergutmacht. Die Straftat darf aber nur mit einer Geldstrafe oder mit Gefängnisstrafe bis zu einem Jahr bedroht sein.

Es ist wichtig, auch über die einstweilige Verfügung zu sprechen. Eine einstweilige Verfügung gemäß $\S 493$ Abs. 1 und 2 StPO wird durch die Staatsanwaltschaft mit der Anklageschrift für die Straftaten bei Gericht beantragt, für welche Geldstrafen oder Gefängnisstrafen von bis zu drei Jahren verhängt werden können. Die einstweilige Verfügung soll lediglich einen dringlichen Anspruch einstweilen sichern und keine endgültigen Tatsachen - wie ein rechtskräftiges Urteil - schaffen. Die Staatsanwaltschaft kann die Verhängung einer oder mehrerer der folgenden Maßnahmen beantragen: Geldstrafe, Fahrverbot, Anordnung der Veröffentlichung des Urteils, Beschlagnahme der Sache, die durch die Straftat erlangt wurde.

An einem Strafverfahren nehmen folgende Hauptbeteiligte teil:

- der Angeklagte (und sein Anwalt),

- der Geschädigte (und seine Vertreter),

- der Richter,

- der Staatsanwalt und

- die Polizei.

An dem Verfahren vor der Anklageerhebung nehmen die Staatsanwaltschaft, die Polizei und der Untersuchungsrichter teil. Vor Einleitung eines Strafverfahrens durch die Staatsanwaltschaft kann die Polizei erste Schritte gemäß §§ 69-93 StPO zur Aufklärung einer Straftat unternehmen. Dann folgt auf die Untersuchungsphase die Anklage und die Phase der Erklärung. Das bedeutet, klarzustellen, dass für die Straftat es darum geht, wer der Täter ist, und welche Erkenntnisse vorliegen. Wenn der Staatsanwalt zu dem Schluss kommt, dass der Zustand der Sache klar genug ist, hebt er die Anklage. Danach folgt im Verfahren die Stufe der Hauptverhandlung (im kosovarischem Strafverfahren wird dieser Abschnitt als Gerichtsverhandlung bezeichnet) und schließlich die Stufe der Rechtsmittel. Rechtsmittel oder Beschwerden können nach der Gerichtsentscheidung oder während des Strafverfahrens eingelegt werden, wie es durch das Gesetz festgelegt ist. ${ }^{27}$

Der Staatsanwalt kann eine Untersuchung und das Strafverfahren einleiten oder nach $§ 79$ StPO zusätzliche Informationen fordern. Wenn der Staatsanwalt Grund zu der Annahme hat, dass eine Straftat begangen worden ist, gerade begangen wird oder die Begehung kurz bevorsteht, kann er selbst nach $\S 90$ StPO verdeckte oder technische Maßnahmen genehmigen oder bei dem Untersuchungsrichter eine Genehmigung beantragen. Die verdeckten oder technischen Maßnahmen der Untersuchung sind in $\S \S 86-100$ StPO aufgeführt. In $\S 101$ StPO sind zwei Optionen vorgesehen, die der Staatsanwalt zu Beginn des Strafverfahrens ergreifen kann.

Wenn dem Staatsanwalt ein begründeter Verdacht hinsichtlich einer begangenen

27 Smibert, John, Udhëzues për Kodin e Procedurës Penale të Kosovës dhe Kodi i Procedurës Penale të Kosovës, Prishtina 2013, S. 3. 
Straftat vorliegt, kann er die Untersuchungsphase nach $\S 112$ StPO einleiten. Andererseits kann er, wenn er gute Verdachtsgründe dafür hat, dass eine Straftat begangen wurde, die mit bis zu drei Jahren Haft sanktioniert wird, die Anklage sofort ruhen lassen. Durch die Strafanzeige der Polizei nach § 102 Abs. 1 StPO kann die Staatsanwaltschaft mit den Ermittlungen beginnen. Die Ermittlungen werden durch den Beschluss der Staatsanwaltschaft gemäß § 104 StPO in Gang gesetzt.

In der neuen StPO ist eine neue Regelung in $\S 154$ bezüglich der Überprüfung der Strafsache durch die Staatsanwaltschaft vorgesehen. Auf der Basis dieser Regelung muss die Staatsanwaltschaft innerhalb einer regelmäßigen Frist von drei Monaten die Strafsache erörtern, um zu entscheiden, ob es weiterer Ermittlungshandlungen bedarf. In diesen Fällen kann die Staatsanwaltschaft das Verfahren für weitere Ermittlungen offen lassen, es vorläufig einstellen oder Anklage erheben. Mit dieser Regelung hat der Gesetzgeber im Sinn, die Staatsanwälte im Kosovo zu disziplinieren. ${ }^{28}$ Diese Vorschrift steht im Einklang mit Art. 6 Abs. 1 EMRK, der unter anderem besagt, dass jede Person ein Recht darauf hat, dass über eine gegen sie erhobene strafrechtliche Anklage von einem unabhängigen und unparteiischen Gericht in einem fairen Verfahren, öffentlich und innerhalb angemessener Frist verhandelt wird.

Der Staatsanwalt kann sich die Beweise im Ermittlungsverfahren der Mithilfe des gesamten Polizeiapparates und aller anderen Behörden bedienen. Dazu gehören insbesondere Zeugenvernehmungen und Sachverständiger. Sie kann aber auch durch Medienberichte, die den Verdacht begründenden Tatsachen erfahren. Allerdings ist in $\S 119$ Abs. 4 StPO vorgesehen, dass dem Angeklagten und dem Opfer das Recht zusteht, von der Staatsanwaltschaft zu fordern, die Beweise während der Untersuchung zu sammeln. Die Zeugenvernehmung ist die einfachste Form der Befragung und ist in erster Linie in $\S 131 \mathrm{StPO}$ geregelt. Dies gilt vor allem für die erste Vernehmung von Zeugen, deren Aussagen nicht entscheidend sind. In schwereren Fällen kann die Aussage schriftlich transkribiert oder auf Audio- oder Videoträger aufgezeichnet werden. Der Staatsanwalt, der Angeklagte und der Geschädigte haben die Möglichkeit, Zeugen zu befragen. § 123 Abs. 3 StPO und die EMRK sehen vor, dass die Aussage im Ermittlungsverfahren nicht das einzige oder entscheidende Kriterium für die Bestrafung einer Person sein darf. Diese Aussage muss durch andere Beweismittel gestützt werden. Der Staatsanwalt kann Sachverständige (Gutachter) gemäß $\S 136$ und 137 StPO beauftragen. Auch der Angeklagte kann gemäß § 141 StPO Experten (Gutachter, Sachverständige) hinzuziehen. Bei einer nicht auflösbaren Uneinigkeit unter den Experten können der Staatsanwalt oder das Gericht gemäß § 142 StPO die Ansicht weiterer Fachleute anfordern.

$\S 163$ StPO setzt der vorläufigen Festnahme und Polizeihaft Grenzen für die Zeit vor der Anklageerhebung, während die Festnahme während der Untersuchung bis zur Verhaftung durch die Bestimmungen in $\S 164$ StPO geregelt wird. Der Staatsanwalt kann gemäß $\S 173$ StPO beim Untersuchungsrichter Maßnahmen zur Sicherstellung der Anwesenheit des Beklagten im Strafverfahren beantragen. Eine Verbesserung in der neuen Strafprozessordnung ist die Einbeziehung von Einziehungsverfahren in das Strafverfahren. In $\S 96$ des neuen StGB ist vorgesehen,

28 Sahiti, Ejup, Murati, Rexhep, E Drejta e procedurës penale, Prishtina 2013, S. 319. 
dass niemand materiellen Nutzen aus einem Verbrechen ziehen darf, weshalb das Gericht eine materielle Beschlagnahme anordnen kann. Wenn keine Anklage erhoben wird, wird das Strafverfahren in Übereinstimmung mit den Fristen des $\S 159$ StPO beendet. Die Strafermittlungen können zur Beendigung der Untersuchung nach § 158 StPO, zur Vereinbarung der Schuldanerkennung durch den Täter nach § 233 StPO oder zur Anklageerhebung gemäß $§ 241$ StPO führen. Die Vereinbarung über die Schuldanerkennung kann nun von dem Beklagten sowie dem Staatsanwalt beantragt werden. Wenn die Verhandlungen über die Vereinbarung zu einer Schuldanerkennung in einer schriftlichen Form führen, kann der Staatsanwalt dem Gericht eine mildere Strafe gemäß $§ 233$ Abs. 7 StPO vorschlagen. Mit der Anklageerhebung endet die Beteiligung des Untersuchungsrichters in dem Verfahren.

Unter dem Zwischenverfahren versteht man jenes Verfahrensstadium, welches zwischen der rechtskräftigen Versetzung in den Anklagestand und dem Beginn der Hauptverhandlung liegt. Es können einzelne Verfahrensschritte bis zur Durchführung der Hauptverhandlung eingeleitet werden. So wird das Verfahren einschließlich der gerichtlichen Hauptverhandlung von einem einzelnen Richter durchgeführt, wenn die Anklage gemäß $\S 19$ Abs. 25 und $\S 25$ Abs. 3 StPO bei der allgemeinen Abteilung erhoben wird. Wenn die Anklage gemäß $\S \S 19$ Abs. 4 und 25 Abs. 4 StPO beim Gericht in der Abteilung für schwere Verbrechen eingereicht wird, wird das Verfahren durch den Vorsitzenden des Gerichtsverfahrens geleitet, während die gerichtliche Hauptverhandlung von einer Kammer durchgeführt wird, die aus einem vorsitzenden Richter und zwei Berufsrichtern besteht.

Hervorzuheben ist, dass nach der aktuellen StPO die Beteiligung der Bürger als Laienrichter deutlich eingeschränkt ist. Eine Ausnahme existiert jedoch in $\S$ 51 Abs. 1 JGG. In dieser Vorschrift ist geregelt, dass in jeder Instanz Laienrichter im Zusammenhang mit jugendlichen Straftätern mitwirken. In § $245 \mathrm{StPO}$ wird konkretisiert, welche der Konfliktparteien zu Beginn des ersten Strafverfahrens teilnehmen können. Nach diesem Paragraph sind Beteiligte des ersten Strafverfahrens die Staatsanwaltschaft, der/die Angeklagte/n und ihre Verteidiger. § 242 Abs. 1 StPO sieht nicht ausdrücklich die Teilnahme des Geschädigten am Verfahren vor, jedoch gibt es nach Meinung von Sahiti / Murat ${ }^{29}$ kein gesetzliches Hindernis, dass auch er in diesem Verfahrensstadium anwesend ist. Während des ersten Verfahrens wird der Richter das zweite Verfahren in einer Zeitperiode von 30 - 40 Tagen bestimmen. Diese Regelung ist nicht verpflichtend, denn der Richter kann von dem zweiten erörterten Strafverfahren absehen. Wie $\S 250$ Abs. 1 StPO vorsieht, wird der Richter während der ersten Erörterung des Strafverfahrens den Angeklagten bzw. seinen Verteidiger über die Möglichkeit der Beschwerde bezüglich der Anklagepunkte informieren.

Bei der Überprüfung der Anklage durch den Vorsitzenden des Spruchkörpers oder durch den Richter als Einzelrichter gemäß § 248 StPO Abs. 4 StPO können diese mit Beschluss ein Schuldanerkenntnis des Angeklagten anerkennen, wenn sie der Meinung sind, dass die Beweise hinsichtlich des Schuldbekenntnisses verifiziert sind. Der Richter fährt dann mit der Verkündung der Strafe fort, bestimmt das Verfahren über eine andere Beweissammlung für die Bestrafung oder bestimmt, das Verfahren

29 Sahiti, Ejup, Murati, Rexhep, E Drejta e procedurës penale, Prishtina 2013, S. 339. 
vorübergehend auszusetzen, solange der Angeklagte mit der Staatsanwaltschaft kooperiert. Die neue Regelung der Vereinbarung über das Schuldbekenntnis in der Hauptverhandlung ist in $\S 233$ Abs. 2 StPO enthalten.

Die neuere Entwicklung ist gekennzeichnet durch einen verstärkten Ausbau der Angeklagtenrechte. Der Angeklagte hat gemäß § 154 Abs. 8 StPO Anspruch auf Wiedereinsetzung in den vorigen Stand der Beweissammlung vor der zweiten Erörterung des Verfahrens. Die Gründe dafür können folgende sein: Es handelt sich nicht um eine Straftat; es bestehen Umstände, die die Schuld ausschließen; die Tat ist verjährt; es wurde das Gnadenrecht ausgeübt; es existieren andere Gründe, die die Verfolgung verhindern; oder es gibt keine ausreichenden Beweise für die dem Angeklagten zur Last gelegte Straftat.

Findet die zweite Erörterung des Strafverfahrens durch den Richter statt, kann er folgende Schritte unternehmen: Er kann das Anhörungsverfahren ansetzen, wenn er es für nötig hält, oder er kann schriftlich die Hauptverhandlung anberaumen. Die Hauptverhandlung wird vertagt, wenn der Angeklagte im ersten oder zweiten Erörterungsverfahren nicht anwesend war. Dann können der Einzelrichter oder der Vorsitzende der Gerichtsverhandlung einen Strafbefehl gegen den Angeklagten anordnen (§ 285 Abs. 4 StPO).

$\S 288$ Abs. 1 StPO sieht vor, dass alle Beteiligten im Strafverfahren einen Experten anfordern können. Im Weiteren wird dieses Recht in diesem Zusammenhang auch in $\S \S 140$ Abs. 2.1 und 137 Abs. 2.1. StPO gewährt.

Die Hauptverhandlung ist das zweite Strafverfahrensstadium. Sie kann gemäß § 240 Abs. 1 StPO ausschließlich durch die Erhebung der schriftlichen Anklage durch die Staatsanwaltschaft durchgeführt werden. In dieser Phase der Hauptverhandlung werden die Schuld und die Strafe des Angeklagten bewertet. Er muss grundsätzlich in der Hauptversammlung anwesend sein. Das Gericht, welches die Verhandlung führt, muss ordnungsgemäß besetzt sein. Gemäß $§ 285$ Abs. 1 StPO bestimmt der Richter als Einzelrichter oder der vorsitzende Richter den Tag, die Uhrzeit und den Ort der Hauptverhandlung. Es werden gemäß § 256 StPO auch die Zeugen und Sachverständigen zur Hauptverhandlung eingeladen. Dem Angeklagten muss eine Frist von acht Tagen zur Verteidigung ab Erhalt der Ladung zum Termin gewährt werden. An einer Hauptverhandlung kann gemäß § 287 StPO auch die Ombudsperson teilnehmen. Die Hauptverhandlung gliedert sich in folgende Schritte:

- Eröffnung;

- Beginn der Gerichtsverhandlung (Hauptverhandlung) und die Erklärung des Angeklagten;

- Beweiserörterung.

Die Hauptverhandlung ist öffentlich. Eine Ausnahme nach $\S 301$ Abs. 2 StPO ist dann gegeben, wenn die Hauptverhandlung ohne Hindernisse nicht durchgeführt werden kann. Die Prozessleitung obliegt dem Einzelrichter oder dem Vorsitzenden. Er eröffnet, unterbricht und beendet die Verhandlung. Der Richter hat von Amts wegen zu prüfen, dass die Personen, die gemäß $§ \S 297-298$ StPO zur Teilnahme an der Hauptverhandlung verpflichtet sind, stets anwesend sind. Nach der Eröffnung der Hauptverhandlung kommt es zur Befragung des Angeklagten über seine Personalien, 
danach wird ihm das Wort für eine Stellungnahme zur Anklage erteilt. Zuerst wird der Angeklagte gefragt, ob er sich schuldig bekennt. Er hat das Recht, jede Aussage $\mathrm{zu}$ verweigern. Alle Verfahrensparteien besitzen ein Fragerecht, nachdem sie vom Richter bzw. Vorsitzenden dazu das Wort erhalten haben.

Erst nach Vernehmung des Angeklagten erfolgt das eigentliche Beweisverfahren, in dem alle Beweise, die der Wahrheitsfindung dienen können, aufzunehmen sind. Es werden alle Beweise der Strafverfahrensparteien aufgenommen. Die Ablehnung eines Beweisantrages hat das Gericht sofort in der Hauptverhandlung zu begründen. Nachdem die Erörterung der Beweise geschlossen wurde, werden der Einzelrichter bzw. der Vorsitzende der Gerichtsverhandlung gemäß § 352 Abs. 1 StPO das letzte Wort dem Geschädigten und dem Verteidiger geben, um sich zu den verhandelten Tatsachen zu äußern. Gemäß Satz 2 erfolgen die letzten Worte der Strafprozessparteien in einer festgelegten Reihenfolge: zunächst die Staatsanwaltschaft, dann der Geschädigte und zuletzt der Angeklagte.

Urteile müssen am Ende der Hauptverhandlung mündlich und im Namen des Volkes verkündet werden ( $\$ 359 \mathrm{StPO}$ ). Das Gericht ist inhaltlich an das mündlich verkündete Urteil gebunden. Nachdem das Beweisverfahren beendet ist und die Schlussvorträge gehalten worden sind, zieht sich das Gericht zur geheimen Urteilsberatung zurück ( $\$ 357$ Abs. 2 StPO). Nach dieser Beratung verkündet der Einzelrichter oder der Vorsitzende den Urteilspruch (§359 Abs. 1 StPO), gibt für diesen eine kurze Begründung ( $\$ 366$ Abs. 2 StPO) und erteilt die Rechtsmittelbelehrung (§ 368 Abs. 1 StPO). Dementsprechend hat eine Zurückweisung der Anklage, ein Schuldspruch oder ein Freispruch zu erfolgen ( $\$ 362$ Abs. 1 StPO). Nach Abs. 2 kann durch den Urteilspruch auch die Anklage als Ganze oder in Teilen zurückgewiesen werden.

Ein Urteilspruch in Form einer Zurückweisung der Anklage gemäß § 363 Abs. 1. Nr. 1-3 StPO erfolgt, wenn

- die Staatsanwaltschaft die Anklage in der Zeit von der Eröffnung bis zur Abschließung der Hauptverhandlung zurückzieht,

- der Angeklagte für dieselbe Straftat durch rechtskräftigen Urteilspruch bereits verurteilt oder freigesprochen wurde oder das Verfahren gegen ihn aufgrund rechtskräftigen Beschlusses eingestellt worden ist, oder

- die Straftat verjährt ist oder eine Amnestie oder Begnadigung stattgefunden hat.

- $\mathrm{Zu}$ einem Freispruch kann es nach $\S 364$ Abs. 1 Nr. 1 - 3 StPO kommen, wenn

- die vorgeworfene Tat nicht strafbar ist,

- Umstände vorliegen, die die Verantwortlichkeit (Strafbarkeit) ausschließen, oder

- dem Angeklagten die vorgeworfene Tat nicht nachgewiesen werden kann (,in dubio pro reo").

Wenn ein Schuldspruch gegenüber dem Angeklagten gemäß § 365 Abs. 1. Nr. $1-6$ StPO ausgesprochen wird, muss der Urteilspruch Folgendes angeben:

- dass das Gericht die Schuld des Angeklagten für voll erwiesen hält (Strafe 
setzt Schuld voraus), welcher Tat der Angeklagte schuldig gesprochen wird bzw. ,unter ausdrücklicher Bezeichnung der durch einen bestimmten Strafsatz bedingten Umstände“, d.h. der Umstände, von denen die Anwendung der Vorschriften des StGB abhängig ist,

- die gesetzliche Qualifikation der Straftat und die gesetzlichen Vorschriften, die im Urteil angewendet werden,

- zu welcher Strafe er verurteilt wird, darüber hinaus wird die Entscheidung über alternative Strafen (gemäß $§ 49 \mathrm{StGB}$ ) getroffen, oder es sind andere Vorschriften des StGB zu beachten, die zu einer Strafbefreiung führen können,

- den Befehl über die Anordnung von Zwangsmaßnahmen für die Rehabilitation der abhängigen Rauschmittelkonsumenten oder über die Beschlagnahme der Vermögensvorteile,

- die Entscheidung über die Anrechnung der Untersuchungshaft oder der vorherigen vollzogenen Strafe und

- die Entscheidung über die Ersetzung der Strafverfahrenskosten.

Mit Hilfe der Rechtsmittel soll die Möglichkeit geschaffen werden, eine Entscheidung der ersten oder zweiten Instanz anzufechten und durch ein höheres Gericht überprüfen zu lassen, ob der Entscheidung ein Fehler im tatsächlichen oder rechtlichen Bereich anhaftet ( $\$ 374$ Abs. 1 - 4 StPO). Die Rechtsmittel müssen in der Regel innerhalb einer bestimmten Frist eingebracht werden (§ 378 Abs. $1-6$ und $\S 380$ Abs. 1 StPO). Im kosovarischen Strafprozessrecht kann von zwei Arten von Rechtsmitteln gesprochen werden: Richtet sich ein Rechtsmittel gegen eine noch nicht rechtskräftig gewordene Entscheidung, spricht man von einem ordentlichen Rechtsmittel. Richtet sich ein Rechtsmittel hingegen gegen eine bereits rechtskräftige Entscheidung, spricht man von einem außerordentlichen Rechtsmittel. Ein Rechtsmittel kann vom Angeklagten selbst oder von anderen Personen (der Staatsanwaltschaft oder dem Geschädigten) eingelegt werden ( $\$ 381$ Abs. 1 StPO). Dabei ist zu unterscheiden, ob das Rechtsmittel zugunsten des Verurteilten oder zu seinem Nachteil erhoben wird. Zugunsten des Angeklagten kann dieser selbst oder sein Verteidiger das Rechtsmittel einlegen. Zum Nachteil und zugunsten des Angeklagten kann die Staatsanwaltschaft ein Rechtsmittel ergreifen (§ 381 Abs. 2 StPO).

\section{e) Das Jugendgerichtsgesetz 2010}

$\S 5$ des Verfahrensgesetzbuchs für Minderjährige von 2010 (in der Folge: JGG) ${ }^{30}$ bestimmt, dass die Vorschriften des StGB und der StPO sowie jedes relevante Gesetz Anwendung finden, außer wenn das JGG selbst anderes vorsieht. Der letzte Satz des $\S 5$ JGG stärkt noch einmal mehr die Vollziehung der Grundsätze der Freiheiten und Menschenrechte, die in der Verfassung inkorporiert sind (z.B. Art. 50 VerfKos über die Kinderrechte).

In $\S 1$ JGG ist der Zweck des Gesetzes bestimmt: „Der vorliegende Kodex regelt

30 Gazeta Zyrtare, Prishtina, Jahr V, Nr. 78, 20. Juli 2010, Kodex Nr. 03/1-193 Jugendgerichtsgesetz (ähnlich wie das deutsche JGG). 
das Verfahren für die Verhängung und Vollstreckung von Maßnahmen und Sanktionen gegen die Jugendlichen im Jugendgerichtsverfahren und im Vermittlungsverfahren."

Gemäß § 17 Abs. 3 StGB sind Unmündige generell nicht strafbar. Nach § $1 \mathrm{Nr}$. 1.1. JGG wird eine Person, die das Alter von 18 Jahren noch nicht erreicht hat, als Kind bezeichnet. § 2 Abs. 1 Nr. 1 JGG bezeichnet als ,jungen Minderjährigen“ jede Person im Alter von 14-16 Jahren. Gemäß § 2 Abs. 1 Nr. 1.4 JGG gilt jede Person im Alter von 16-18 Jahren als ,erwachsener Minderjähriger“ und gemäß § 2 Abs. 1.5. JGG jede Person im Alter von 18-21 Jahren als ,junger Erwachsener“.

Das Jugendstrafrecht betont deutlich den Schutz des minderjährigen Straftäters. Im Jugendstrafverfahren sollen im Zusammenhang mit Jugendstraftaten primär Personen tätig sein, welche besondere pädagogische Kenntnisse haben. Da es im Kosovo auch einen Untersuchungsrichter gibt, muss auch dieser ein Jugendrichter sein.

Das JGG differenziert zwischen jüngeren und älteren minderjährigen Straftätern, wobei eine Altersgrenze bei 16 Jahren gezogen wird. Eine Besonderheit unter den staatlich normierten Diversionsregelungen für Jugendliche ist die in $\S 14$ JGG vorgesehene Form eines außergerichtlichen Tatausgleichs im Strafrecht, die als strafrechtliche Mediation in Form eines außergerichtlichen Verfahrens normiert ist. Es ist wichtig zu betonen, dass nach aktuellem JGG für die sog. ,jungen Minderjährigen “ ausschließlich diversionelle Maßnahmen und Erziehungsmaßnahmen ausgesprochen werden können. In der kosovarischen Rechtsordnung wird dem jugendlichen Straftäter im Gegensatz zum Erwachsenen der diversionelle Weg auch im Strafverfahren nach Anklageerhebung ermöglicht. Im Jugendstrafrecht gilt aber das Diversionsverbot bei Straftaten mit Todesfolge. Im Diversionssystem gilt insbesondere die Regel, dass bei Jugendlichen, die eine Straftat aus Fahrlässigkeit begangen haben, die mit bis zu fünf Jahren Freiheitsstrafe bedroht ist, eine diversionelle Maßnahme angewendet werden kann. Das ist ein Unterschied zum Erwachsenenstrafrecht, in dem ein Höchstmaß von drei Jahren Freiheitsstrafe gilt. In Fällen, in denen eine strafbare Handlung zum Tod eines Menschen geführt hat, kommen diversionelle Maßnahmen grundsätzlich nicht in Betracht.

Die diversionellen Maßnahmen umfassen eine Reihe von Optionen, ein Strafverfahren gegen jugendliche Täter ohne Ergehen eines Urteils zu beenden. Vorgesehen sind beispielsweise:

- die Vermittlung zwischen Täter und Opfer unter Einschluss einer persönlichen Entschuldigung des minderjährigen Täters beim Opfer;

- die Vermittlung zwischen dem Minderjährigen und seiner Familie;

- die Schadenswiedergutmachung durch den Täter im Rahmen eines außergerichtlichen Tatausgleichs;

- die Verpflichtung zu regelmäßigem Schulbesuch sowie zur Aufnahme einer Beschäftigung und Ausbildung;

- die Verpflichtung zur Teilnahme an verkehrserziehenden Maßnahmen;

- die Inanspruchnahme psychologischer Beratung.

Nach einem Bericht der Staatsanwaltschaft wurde eine Diversion im ersten 
Quartal 2013 in 77 von 667 insgesamt erledigten Strafanzeigen und somit in 11,5 \% der Fälle unmittelbar von der Staatsanwaltschaft angeordnet. ${ }^{31}$

Nach einer Regelung aus dem Jahre 2004 ist eine Gefängnisstrafe unter sechs Monaten nicht zulässig, sondern es ist stattdessen eine alternative Maßnahme anzuordnen (§§ 8, 17 und insb. § 34 JGG). Nach § 34 Abs. 2 S. 1 JGG sind Freiheitsstrafen grundsätzlich nur zwischen sechs Monaten bis maximal fünf Jahren zulässig. In Ausnahmefällen können bis zu zehn Jahre Gefängnis als Strafe verhängt werden. Mit bis zu maximal zehn Jahren Gefängnis wird ein Jugendlicher nur bestraft, wenn dieser eine Straftat begangen hat, welche mit einer langen Gefängnisstrafe (20 Jahre oder länger) bedroht ist bzw. wenn er zwei Straftaten in Tateinheit begangen hat und jede Tat mit mindestens 10 Jahren Gefängnis bedroht ist (§ 34 Abs. 2 S. 2 JGG).

\section{f) Das Mediationsgesetz 2008}

Als Folge der historischen Tradition der Konfliktlösungen durch das albanische Gewohnheitsrecht ${ }^{32}$ trat im Kosovo 2008 ein Mediationsgesetz (in der Folge: MedG) in $\mathrm{Kraft}^{33}$. Das Mediationsgesetz hat seine traditionellen Wurzeln im Gewohnheitsrecht, worauf auch die Präambel des Mediationsgesetzes hinweist ${ }^{34}$. Mediation wird im Strafrecht als „das Institut des Strafrechts, das die alternative Lösung der strafrechtlichen Angelegenheiten zwischen den Subjekten des Rechts auf außergerichtlichem Wege ermöglicht" bezeichnet. Durch dieses Gesetz werden Konflikte im zivilrechtlichen sowie auch im strafrechtlichen Bereich gelöst. Das Mediationsgesetz soll im Fall von Straftaten bei geringerer Schuld sowie für - meist jugendliche - Ersttäter Anwendung finden. Ein Interview des Verfassers dieser Arbeit mit Blerta Ahmetaj, der Geschäftsführerin des Zentrums der Mediation in Prishtina, am 6.8.2014 bestätigte, dass strafrechtliche Mediation v.a. bei Strafdelikten im Straßenverkehr, bei Delikten wie häuslicher Gewalt, leichter Körperverletzung, Diebstahl, Bedrohung, Erpressung und Verstößen im Zusammenhang mit öffentlichen Dienstleistungen (wie z.B. Entziehung elektrischer Energie) angeordnet und durchgeführt wird. Das Verfahren der Mediation ist in den $\S \S 8-14$ MedG 2008 geregelt. Die strafrechtliche Mediation ist auch in $\S 232$ StPO (2013) bei den sog. „alternativen Verfahren“ vorgesehen. Bei jugendlichen Straftätern gilt die spezielle Regelung des $\S 14$ JGG. Die strafrechtliche Mediation bei Erwachsenen ist zulässig bei Straftaten, deren Strafmaß bei höchstens drei Jahren Gefängnisstrafe liegt. Bei Jugendlichen bestehen nach JGG für diversionelle Maßnahmen folgende Voraussetzungen hinsichtlich der drohenden Strafe:

- eine Strafandrohung von bis zu drei Jahren Gefängnisstrafe oder Geldstrafe,

31 Raport për punën e Prokurorive Themelore, Prokurorisë Speciale të Republikës së Kosovës, Prokurorisë së Apelit dhe Prokurorisë së Shtetit, Këshilli Prokurorial i Kosovë (Bericht über die Arbeit der Staatsanwälte der ersten Instanz, der Spezial-, der Berufungsstaatsanwaltschaft sowie des Staatsanwaltschaftsrates des Kosovos), Pristina 2013, S. 8.

32 Qerimi, Islam, Informelle Konfliktschlichtung nach albanischem Kanun. Eine rechtsvergleichende Analyse zum alten Kanun und modernen Recht, Hamburg, 2016.

33 Gesetz Nr. 03/L-57 über die Mediation.

34 Siehe die Präambel des kosovarischen Mediationsgesetzes von 2008. 
falls die Tat vorsätzlich begangen wurde;

- eine Strafdrohung von bis zu fünf Jahren Freiheitsstrafe, falls die Tat fahrlässig begangen wurde;

- die Tat hat nicht den Tod eines Menschen zur Folge gehabt, wobei es auf die Begehungsform nicht ankommt.

\subsection{STRAFRECHTLICHE NEBENGESETZE}

Außer den genannten Gesetzbüchern (StGB, StPO und JGG) gibt es im kosovarischen Recht auch einige andere Gesetze, die auf den strafrechtlichen Bereich fokussiert sind. Diese sind:

- Gesetz über die Vollstreckung strafrechtlicher Sanktionen (Gesetz Nr. 04/L149);

- Antikorruptionsgesetz (Gesetz Nr. 2004/34);

- Gesetz zur strafrechtlichen Verantwortung von juristischen Personen (Gesetz Nr. 04/L-30);

- Gesetz über die Bekämpfung von Geldwäsche und Terrorismusfinanzierung (Gesetz Nr. 03/L-196) mit späteren Änderungen;

- Gesetz zum Schutz vor Gewalt in der Familie (Gesetz Nr. 03/L-182);

- GesetzzurStärkungderRückgewinnungshilfeundderVermögensabschöpfung bei Straftaten (Gesetz Nr. 04/L-140);

- Gesetz zum Schutz der personenbezogenen Informationen (Gesetz Nr. 04/L043);

- Gesetz zum Schutz gefährdeter Zeugen (Gesetz Nr. 04/L-115);

- Gesetz zur Verhinderung und Bekämpfung des kybernetischen Verbrechens (Gesetz Nr. 04/L-136);

- Gesetz über die internationale Zusammenarbeit in strafrechtlichen Angelegenheiten (Gesetz Nr. 04/L-213);

- Gesetz zur Verhütung und Bekämpfung des Menschenhandels und zum Schutz seiner Opfer (Gesetz Nr. 04/L-218);

- Gesetz über die Amnestie (Gesetz Nr. 04/L-209), und

- Gesetz zur Verhinderung der Anschließung an bewaffnete Konflikte außerhalb des Staatsgebietes (Gesetz Nr. 05/L-002).

\section{ZUSAMMENFASSUNG}

In dieser Arbeit wurde dargestellt, dass das kosovarische Straf- und Strafprozessrecht einen langen Weg der Konsolidierung benötigte. Seit dem Mittelalter wurde ein strafrechtliches Gewohnheitsrecht parallel zu der von den Fremdmächten installierten staatlichen Justiz angewendet. Dies war der Fall, solange die Kosovaren unter der Herrschaft Anderer standen, also bis zum Einrücken der UNMIK am 10.06.1999. In vielen Fällen wird das strafrechtliche Gewohnheitsrecht noch heute angewendet. Das heutige kosovarische Strafrecht teilt sich in ein Erwachsenenrecht und ein Minderjährigenrecht. Im Kosovo gibt es im strafrechtlichen Bereich ein 
StGB, eine StPO, ein JGG, ein Mediationsgesetz, welches auch für strafrechtliche Angelegenheiten vorgesehen ist, und andere Nebenstrafgesetze. Sowohl in das StGB (2013) als auch in die StPO (2013) wurden neue Vorschriften aufgenommen, die im Einklang mit der Verfassung des Kosovo (2008) und mit den internationalen Standards der Menschenrechte stehen. Diese Standards sind durch die Unterzeichnung des Assoziierungsabkommens des Kosovo und der Europäischen Union am 15.10.2015 eine Verpflichtung des Kosovo, EU-Standards bei der Regierungsführung und für die Zivilgesellschaft einzuhalten, was etwa den Bereich der Menschenrechte oder rechtsstaatliche Justizverfahren betrifft. Schlussendlich muss konstatiert werden, dass ein EU-Beitritt das Land aus der Isolation führen und seine Entwicklung fördern würde. Mit der EU-Mitgliedschaft würden auch im Kosovo „Demokratie, Menschenrechte und mehr Sicherheit" einkehren. Für den Kosovo ist es verpflichtend, nach dem Vertrag von Lissabon der Europäischen Union von 2009 eine (Mindest-) Harmonisierung des nationalen Strafrechts (Art. 83 AEUV) und seit dem Vertrag von Lissabon auch des nationalen Strafverfahrensrechts aufgrund von EU-Rechtsakten (Art. 82 II AEUV) durchzuführen. Deshalb muss auch das kosovarische Strafrecht klare Regelungen schaffen, die dem nationalen Recht die Möglichkeit der strafrechtlichen Zusammenarbeit in Form der „Annäherung der Strafvorschriften der Mietgliedstaaten, [...] soweit dies erforderlich ist" (Zusammenarbeit in Strafsachen Artikel 26 AEUV, ex-Artikel 29 EUV) eröffnen. Das ist notwendig, da ein Beitritt des Kosovo zu den entsprechenden Abkommen des Europarates am Widerspruch einiger Mitgliedstaaten des Europarates scheitert. Aufgrund dieser Tatsachen wird die Meinung vertreten, dass zu einer Europäisierung des kosovarischen Strafrechts keine Alternative besteht. Wir, Autoren dieses Beitrages, haben die Zuversicht, dass die guten Erfahrungen mit der europäischen Tradition des Strafrechts auch im Kosovo aufgenommen und den zeitgenössischen Umständen entsprechend weiterentwickelt werden.

\section{LITERATUR}

\section{Bücher}

1. Dolenc, Metod, Dodatak k Tumaču Krivičnog zakonika Kraljevine Jugoslavije, verfasst von, Zagreb 1931.

2. Elsie, Robert, Vorwort in: Der Kanun. Das albanische Gewohnheitsrecht nach dem sogenannten Kanun des Leke Dukagjini, kodifiziert von Shtjefen Gjeqovi, ins Deutsche übersetzt von Marie Amelie Freiin von Godin, Peja 2001.

3. Elezi, Ismet, Kanuni i Labërisë, Tiranë 2006.

4. Gashi, Rexhep, Ekzekutimi i denimeve alternative, Prishtina 2013.

5. Illia, Frano, Kanuni i Skënderbeut, Milot 1993.

6. Kanuni i Zhurisë (Jurisë), publiziert in der Zeitschrift: „Përlindja e Shqipnies“, Vlora 1913, neu publiziert in: Jeta Juridike, Nr.1, 2007, S. 4 - 18.

7. Ligja penale otomane, përkthyer në gjuhën shqipe nga Dhimitër Kacimbra dhe av.Koço Tasi, botim i Ministrisë së Drejtësisë, Tiranë 1924 (Justizministerium (Hrsg.): Ligja penale otomane, übersetzt ins Albanische von Dhimitër Kacimbra und Koço Tasi, Tirana 1924).

8. Omari, Luan, Luarasi Aleks, Historia e shtetit dhe e së drejtës në Shqipëri, 1994.

9. Pupovci, Syrja, Marrëdhëniet juridike civile në Kanunin e Lekë Dukagjinit, Prishtina, 1971. 
10. Qerimi, Islam, Informelle Konfliktschlichtung nach albanischem Kanun. Eine rechtsvergleichende Analyse zum alten Kanun und modernen Recht, Hamburg 2016.

11. Raport për punën e Prokurorive Themelore, Prokurorisë Speciale të Republikës së Kosovës, Prokurorisë së Apelit dhe Prokurorisë së Shtetit, Këshilli Prokurorial i Kosovë, Prishtinë 2013, (Bericht über die Arbeit der Staatsanwälte der ersten Instanz, der Spezial-, der Berufungsstaatsanwaltschaft sowie des Staatsanwaltschaftsrates des Kosovos, Pristina 2013).

12. Salihu, Ismet, Zhitija, Hilmi, Hasani, Fejzullah: Kodi Penal i Republikes së Kosovës. Komentar, Prishtina 2014.

13. Sahiti, Ejup, Murati, Rexhep, E Drejta e procedurës penale, Prishtina 2013.

14. Sahiti, Ejup, Murati, Rexhep, Elshani, Xhevdet, Kodi i Procedurës Penale, Komentar (GIZ), Prishtina 2014.

15. Smibert, John, Udhëzues për Kodin e Procedurës Penale të Kosovës dhe Kodi i Procedurës Penale të Kosovës, Prishtina 2013.

\section{Zeitschriften}

1. Ambrož, Matjaž, Der Besondere Teil des neuen slowenischen Strafgesetzbuchs, in: Jahrbuch für Ostrecht, Regensburg, Hb. 2Bd. 51 (2010), S. 319 - 332.

2. Küpper, Herbert, Die kosovarische Verfassungsordnung, Jahrbuch für Ostrecht, Regensburg 2008/2, S. 297-350.

\section{Zeitungsartikel}

1. Steiner, Michael, Ein neues Strafrecht für Kosovo, Neue Zürcher Zeitung, 7.7.2003.

Gesetze

1. Gazeta Zyrtare e Republikës së Kosovës, Prishtinë: Kodi Nr.03/L-193 i Drejtësisë Për Të Mitur, 20.08.2010, (Jugendgerichtsgesetz Jahr V, Nr. 78, 20. Juli 2010, Kodex Nr. 03/1193 aus dem Jahr 2010- ähnlich wie das deutsche JGG).

2. Gazeta Zyrtare e Republikës së Kosovës, Prishtinë: Kodi Nr. 04/L-082 Kodi Penal i Republikës Së Kosovës, / Nr.19 / 13 Korrik 2012, (Kosovarisches Strafgesetzbuch NR. 04/L-082 der Republik Kosovo aus dem Jahr 2012).

3. Gazeta Zyrtare e Republikës së Kosovës, Prishtinë: Kodi Nr. 04/L-123 i Procedures Penale / Nr. 37 / 28 Dhjetor 2012, Prishtinë, (Kosovarische Strafprozessordnung Nr. 04/L123 der Republik Kosovo aus dem jahr 2012).

4. Gazeta Zyrtare e Republikës së Kosovës, Prishtinë: LIGji Nr. 03/L-057 Për Ndërmjetësim 01.11.2008, (Gesetz Nr. 03/L-57 über die Mediation der Republik Kosovo aus dem Jahr 2008).

5. Gazeta Zyrtare e Republikës së Kosovës, Prishtinë: Ligji Nr. 03/L-199 Për Gjykatat, Prishtinë: Viti V / Nr. 79 / 24 Gusht 2010 Ligji Nr. 03/L-199 Si Dhe Ligji Nr. 05/L-032 Për Ndryshimin Dhe Plotësimin E Ligjit, (Gesetz Nr. 03/L-199 über die Gerichte der Republik Kosovo, Nr. 79/2010, einschließlich Gesetz Nr. 05/L-032 zur Änderung und Vervollständigung aus dem Jahr 2010).

6. Gazeta Zyrtare e Republikës së Kosovës, Prishtinë: Kodi i Përkohshëm Penal I Kosovës, UNMIK/Rreg/2003/25, 6 korrik 2003, 151, (Vorläufiges Strafgesetzbuch Kosovos aus dem Jahr 2003).

7. Gazeta Zyrtare e Republikës së Kosovës, Prishtinë: Kodi i Përkohshëm i Procedurës Penale i Kosovës Unmik/Rreg/2003/26, 6 korrik 2003, 237, (vorläufige Strafprozessordnung Kosovos aus dem Jahr 2003).

8. Resolution Nr. 1999/1244 in der Sitzung 4011 am 10.06.1999. 
9. Službene novine Kraljevine Jugoslavije: Zakon o zastiti javne bezbednosti i poretka državi, Jahr III, br. 170 A., Beograd 3 August 1921, (Gesetz zum Schutz der öffentlichen Sicherheit und Ordnung des Staates des Jugoslawischem Könisgsreich aus dem jahr 1921).

10. Službeni list FNRJ: Krivični zakonik, 13. Dezember 1947, Belgrad, Broj 106, God. III. (Strafgesetz der ehemaligen Föderativen Volksrepublik Jugoslawien aus dem Jahr 1947).

11. Službeni list FNRJ: br. 13/1951 od 9. 3. 1951. Krivični zakonik FNRJ, 9. März 1951, Belgrad, Broj 13, God. VII, (Strafgesetz der ehemaligen Föderativen Volksrepublik Jugoslawien aus dem Jahr 1951).

12. Službeni list SFRJ: Ustav Socijalističke Federativne Republike Jugoslavije, br. 9, Belgrad, 21.02.1974, (Verfassung der ehemaligen Föderativen Volksrepublik Jugoslawien aus dem Jahr 1974).

13. Službeni list FNRJ: Krivični zakonik Socijalističke Autonomne Pokrajine Kosovo, 1. Juli 1977, (Strafgesetz der ehemaligen Sozialistischen Autonomen Provinz Kosovo aus dem Jahr 1977).

14. Službeni list SFRJ, br. 4, God. XXIII, Zakonik o krivičnom postupku Socijalističke Federativne Republike Jugoslavije, 14. Januar 1977, (Strafprozessordnung der ehemaligen Sozialistischen Föderativen Republik Jugoslawien aus dem Jahr 1977). 


\author{
Islam Qerimi* \\ Bedri Bahtiri**
}

Sažetak

\section{KAZNENO PRAVO I KAZNENO POSTUPOVNO PRAVO U REPUBLICI KOSOVO}

Nakon svoje promjenjive povijesti Kosovo je moglo donijeti svoje vlastito kazneno i kazneno postupovno pravo tek nakon što je steklo neovisnost. Ovaj rad opisuje važeće kosovsko pravo te između ostalog istražuje je li ono u skladu sa smjernicama Ustava i odgovarajućim međunarodnim ugovorima. Čini se da je zakonodavac pri donošenju novog kaznenog prava propustio uključiti delikt nanošenja teške tjelesne ozljede nehajem, iako je takvo činjenično stanje postojalo u prijašnjem KZ. Novo kazneno postupovno pravo obogaćeno je nekolicinom elemenata iz anglosaksonskog prava i ono je uglavnom u skladu sa smjernicama Ustava glede ljudskih prava kao i s EKZLJP. Na mlade počinitelje kaznenih djela primjenjuje se posebno postupovno pravo kao i odmjeravanje kazni, a ono je sadržano u Zakonu o sudovima za mladež. Pravila o mirenju u kaznenim postupcima poduprta su starim običajnim tradicijama rješavanja sporova.

Ključne riječi: kazneno pravo, kazneno postupovno pravo, maloljetničko kazneno pravo, reforma kaznenog prava, Kosovo.

Summary

\section{CRIMINAL LAW AND CRIMINAL PROCEDURE LAW IN THE REPUBLIC OF KOSOVO}

After independence Kosovo could, for the first time in its history, enact its own criminal and criminal procedure law. This essay describes the present Kosovar law and analyses i.a. whether it is in harmony with the requirements of the Constitution and of pertinent international instruments. When the Kosovar parliament enacted the new Criminal Code it seems to have "forgotten" to include the crime of a negligent infliction of serious bodily harm although the previous code had contained such a clause. The new Criminal Procedure Code now contains some Anglo-Saxon elements

* Dr. sc. Islam Qerimi, izvanredni profesor Pravnog fakulteta Sveučilišta u Beču; i_qerimi@ hotmai.com.

** Dr. sc. Bedri Bahtiri, izvanredni profesor, Pravni fakultet Sveučilišta u Prištini; bedri.bahtiri@ uni-pr.edu. 
and meets more or less the human rights requirements of the Constitution and the ECHR. Juvenile criminals fall under a special regime laid down in a separate Juvenile Justice Code. The rules on mediation in criminal matters are based on very old customary traditions of dispute resolution.

Keywords: Criminal Law, Criminal Procedure Law, Juvenile Criminal Law, Criminal Law Reform, Kosovo.

Riassunto

\section{IL DIRITTO PENALE SOSTANZIALE E PROCESSUALE NELLA REPUBBLICA DEL KOSOVO}

In seguito alla sua mutevole storia il Kosovo poté introdurre il proprio diritto penale sostanziale e processuale appena dopo l'indipendenza. Il presente lavoro descrive il diritto kosovaro vigente e, tra l'altro, indaga se esso sia conforme agli orientamenti della Costituzione e dei relativi Trattati internazionali. Pare che il legislatore in occasione dell'introduzione della nuova disciplina del diritto penale abbia omesso di includervi il delitto di lesioni gravi colpose, benché tale stato di fatto esistesse nella precedente legislazione penale. Il nuovo diritto processuale penale è arricchito da un certo numero di elementi di derivazione anglosassone ed esso è perlopiù conforme agli orientamenti della Costituzione per quanto riguarda i diritti fondamentali, come pure alla CEDU. Nei confronti dei giovani autori di reati si applica un diritto processuale penale speciale, come anche per la comminazione della pena, che si trova nella Legge sui tribunali per la gioventù. Le regole sulla conciliazione nei procedimenti penali sono supportate da vecchie tradizioni consuetudinarie relative alla risoluzione delle controversie.

Parole chiave: Diritto penale, diritto processuale penale, Diritto minorile penale, riforma del diritto penale, Kosovo. 
